\title{
Failure pressure evaluation of the containment building of a large dry nuclear power plant
}

\author{
Alex H. Barbat a, Miguel Cervera ${ }^{\text {a }}$, Alex Hanganu ${ }^{a}$, Cruz Cirauqui ${ }^{\text {b }}$ \\ Eugenio Oñate ${ }^{\mathrm{a}, \mathrm{b}, *}$ \\ a Escuela Técnica Superior de Ingenieros de Caminos, Canales y Puertos, Technical University of Catalonia, Gran Capitán s/n, \\ Edificio C1, 08034 Barcelona, Spain \\ ${ }^{\mathrm{b}}$ International Center for Numerical Methods in Engineering (CIMNE), Gran Capitán s/n, Edificio C1, 08034 Barcelona, Spain
}

\begin{abstract}
The evaluation of the failure pressure of the containment building of a large dry PWR-W three loops nuclear power plant, based on computer numerical simulation, is described in this paper. The proposed method considers fully three-dimensional finite element models in order to take into account the effect of the most significant structural characteristics (presence of three buttresses, penetrations, additional reinforcement around the penetrations, etc.), the lack of symmetry of the forces generated by the prestressing system, as well as the nonlinear behaviour of the materials and the sensitivity of the results to uncertainties associated with several parameters. The computational model is completely described, including the constitutive equations for the concrete, the reinforcing steel and prestressing tendons, the spatial discretization-isoparametric elements including the reinforcement are used. The structural models and the analyses performed for their calibration are also described. The influence on the failure pressure of incorporating the foundation slab in the structural model, and the influence of the thermal effects, are discussed. One of the conclusions of the numerical study is that the failure process can be appropriately simulated by means of a structural model which does not include either the foundation slab or the thermal effects. Finally, results of a probabilistic simulation of the failure pressure are given. (c) 1998 Elsevier Science S.A. All rights reserved.
\end{abstract}

\section{Introduction}

The risk of a nuclear power plant is related to the potential for the release of radioactive material. The safety of these installations is based on the concept of 'defence in depth', which means the establishment of different barriers to avoid or

\footnotetext{
* Corresponding author. Current address: Universitat Politécnica de Catalunya, Departament de Resistència de Materials i Estructures a l'Engineria, Campus Nord UPC, Gran Capitán s/n, 08034 Barcelona, Spain.
}

mitigate such release. The last of these barriers is the containment building, whose design is based on the loads produced by the so-called Design Basis Accident (DBA).

Starting from the experience of the Three Mile Island accident, the possibility of occurrence of accidents with potential consequences greater than the corresponding DBA has been recognized, that is, there are very low probability accident sequences that can progress to core damage and, in certain cases, to vessel failure. If this occurs, different in-vessel and ex-vessel phenomena would 
appear, like static pressurization, hydrogen combustion, direct containment heating, vapour explosion, etc., that can produce pressure increases inside the building beyond the design pressure (De Boeck, 1992).

The objective of the present paper is to present a method and results for the evaluation of the capacity of a large dry containment building to resist loads beyond the design ones, especially those arising from internal pressure. The main purpose of the analysis is to determine the ultimate pressure, that is the maximum internal pressure for which it is possible to guarantee the behaviour of the building as a fission product barrier. Previous works (IDCOR, 1983; Parks et a1., 1992) have obtained failure pressures between 2.5 and 3.0 times the design one for large dry containment buildings. The study of local phenomena such as liner tearing is beyond the scope of this work.

In the present work, the ultimate internal pressure is computed by means of a nonlinear structural analysis and compared with the design one, an actual safety coefficient being thus obtained. The proposed method for evaluating the failure pressure is based on con complete failure process (3D) finite element model. inclusion in the analyses of those structural elements - buttresses, large-sized penetrations, additional reinforcement around the penetrations-

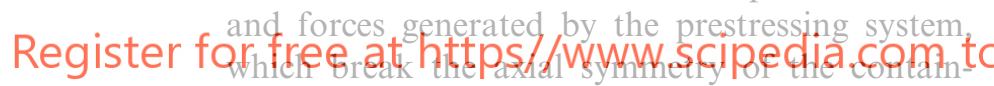
ment building. The failure pressure of the structure is defined as the pressure corresponding to a certain strain limit of the reinforcement steel, prestressing tendons and liner.

Different finite element models for the analysis of reinforced concrete structures have been proposed since 1967 when, for the first time, a nonlinear concrete model was used to describe the behaviour of reinforced concrete beams ( $\mathrm{Ngo}$ and Scordelis, 1967). Finite element models for twoand three-dimensional frames, plates and shells are available today (ASCE Committee on Concrete and Masonry Structures, 1982; Cervera, 1986; Hofstetter and Mang, 1995). Among the most popular models, we can quote those based on smeared crack theory using elasto-brittle (Cervera and Hinton, 1986; Cervera et al., 1987a,b, 1990; Oñate et al., 1988), elasto-damage (Cervera et al., 1992, 1995a) and elasto-plasticdamage (Oller, 1988; Lubliner et al., 1989; Faria and Oliver, 1993) constitutive theories. The most important parameters characterizing the actual mechanical behaviour of concrete have been included in the computational models, their effectiveness being thus improved (Bićanić and Mang, 1990; Mang et al., 1994). Therefore, a reliable evaluation of the structural safety of reinforced and prestressed concrete structures, like the containment building of nuclear power plants, is now possible with the new available methodologies.

The structure of the containment building of the large dry nuclear power plant studied, the analysis strategy and the computational model used in the evaluation of the failure pressure are first described in this paper. The structural models and their calibration are then discussed. The most important results for the performed deterministic analysis are then given, followed by a probabilistic study considering uncertainties in the main
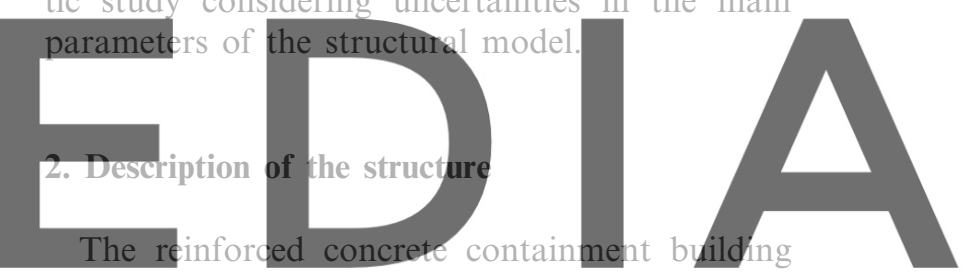

which hosts the reactor core and its cooling system consists of a massive foundation slap and a

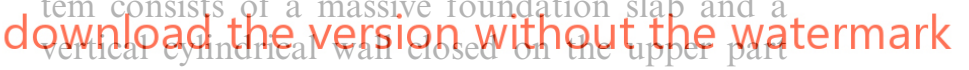
by a hemispherical dome. The structure has an additional prestressing system for the wall and the dome consisting of non-adherent tendons, and its interior is protected with a steel liner having a sealing role. Fig. 1 shows vertical and horizontal cross-sections of the structure, including the main geometrical parameters. The most important dimensions of the structure are: interior diameter of the wall $40 \mathrm{~m}$, interior total height $63.4 \mathrm{~m}$, interior height of the cylinder $43.4 \mathrm{~m}$, thickness of the foundation slab $3 \mathrm{~m}$, thickness of the cylindrical wall $1.15 \mathrm{~m}$, thickness of the dome at its highest point $0.95 \mathrm{~m}$, average liner thickness $6.5 \mathrm{~mm}$.

There are three vertical buttresses on the outer side of the cylindrical wall spaced at $120^{\circ}$, which 


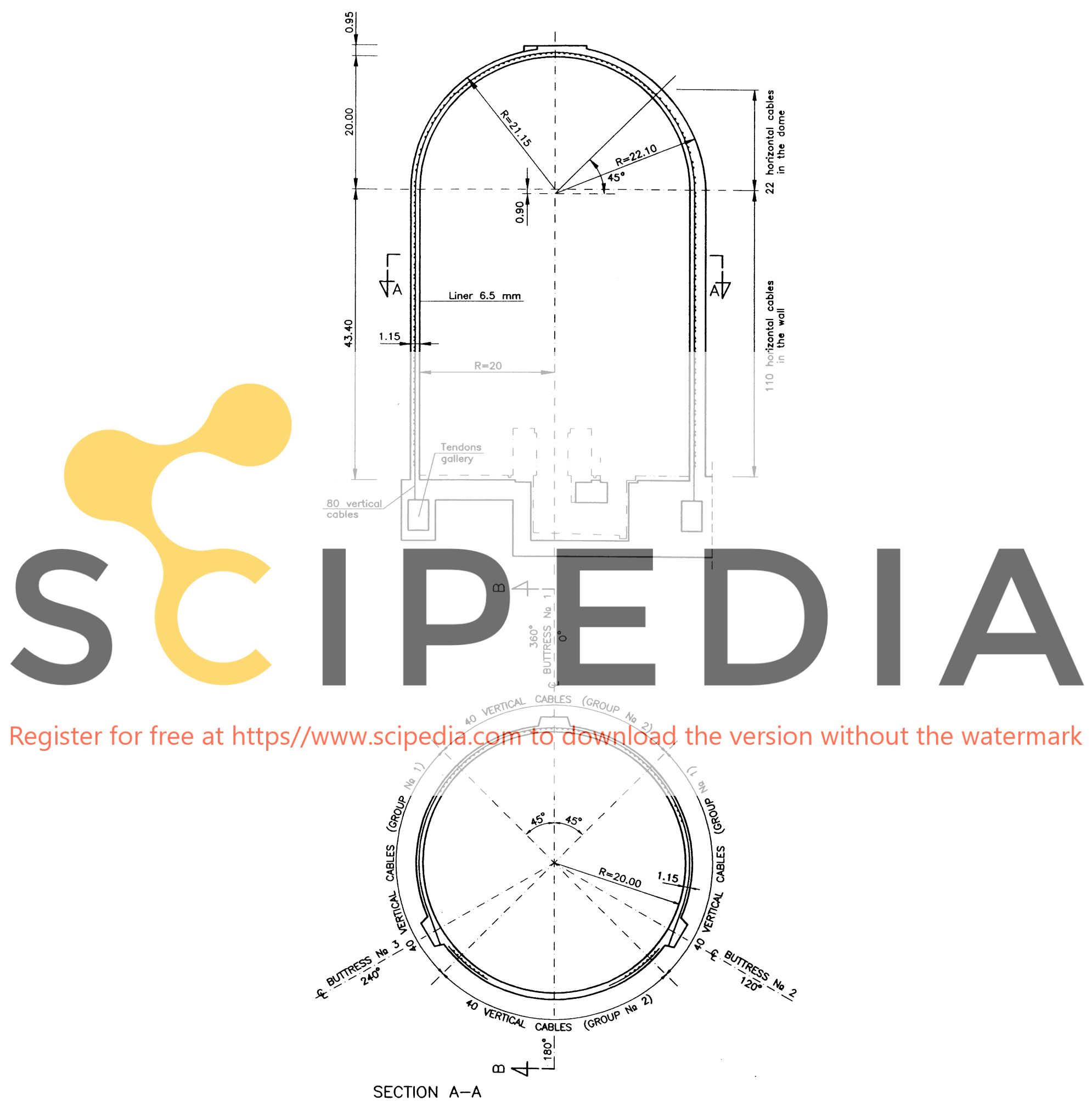

Fig. 1. Containment shell: (a) vertical section; (b) horizontal section. 
serve as support for the horizontal prestressing system. The penetrations in the cylindrical walls having a major relevance in the structural behaviour are: the personnel airlock, the equipment hatch, the emergency airlock, the main steam penetration, the fuel transfer penetration and the purge line penetration.

The prestressing system is shown in Fig. 1. There are 132 horizontal tendons, with an angle of $240^{\circ}$ each, anchored in the three buttresses and 80 vertical tendons in two families $(\mathrm{N}-\mathrm{S}, \mathrm{E}-\mathrm{W})$ anchored in a perimetrical gallery located in the lower part of the foundation slab.

\section{Strategy of analysis}

The failure pressure of the containment building studied, corresponding to an accident, is computed in this study by means of a nonlinear finite element analysis. The structure is subjected to a sequence of loads obtained from a specified accident scenario, consisting in simultaneous increments of the inner pressure and temperature while the outer face was kept plained previously, the as the inner pressure corr tural material exhaustion. that strain limit of the reinforcement steel, prestressing tendons and liner. The failure criterion considered in the containment building studied assumes that failure occurs when the strain limit mentioned

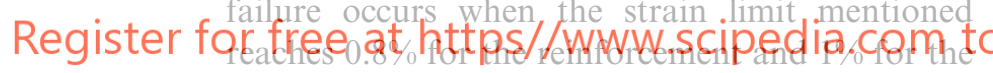
tendons.

This paper does not address the issue of liner scratching as an independent 'loss of containment' failure mode, which was recognized as a failure risk following the $1 / 6$ scale Sandia experiment (Clauss, 1989; EPRI, 1989; Hanson et al., 1989). Due to the high ductility of the liner $(20 \%)$ compared with the underlying low ductility accepted for the rest of the structural components $(0.8 \%)$, this mode can occur only at singular locations where unbonding between the concrete wall and the liner can happen in relatively large areas. Due to the deformation compatibility, the inclusion of this failure mode would have required a considerable increase in complexity of the finite element structural model, as it needed to consider each of the anchorage bars and angles between the liner and the wall, which is beyond the scope of this study.

Different approaches have been used in other studies to evaluate the failure pressure of containment buildings. A popular approach consists in performing simplified computations of specific risk locations of the structure, estimating the failure pressure of each of them and assigning as failure pressure the lowest of all the obtained pressures. Another method requires a first analysis by means of a simplified axisymmetrical finite element model, from which the boundary conditions for a more detailed analysis of specific loca-

tions are deduced (IDCOR, 1983). As an alternative, in the present study a 3D nonlinear finite element structural model able to describe the most significant characteristics of the structure is used. The most important reasons for choosing a 3D model instead of an axisymmetrical one are the following:

- presence of three buttresses on the outer part

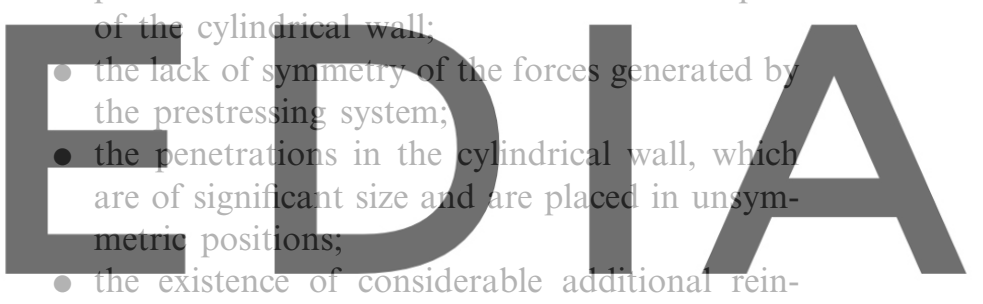

forcement around the penetrations.

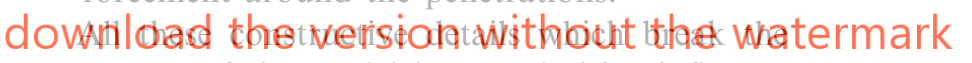
symmetry of the model have a decisive influence on the deformation modes of the structure, which can be detected only by means of a 3D model.

The method used to evaluate the failure pressure can be summarized in the following points:

- Definition of the elements of the computational model required in order to simulate the structural behaviour in the intermediate phases and until the failure condition is met;

- Development of a discrete structural model capable of describing adequately the actual structural behaviour;

- Calibration of the structural model through the numerical simulation of the integrity test of the containment building (static analysis); 
- Simulation of the progressive structural damage process during an accident scenario in which the pressure increases until the failure occurs (nonlinear analysis);

- Sensitivity study of the results against changes in two relevant circumstances: the inclusion in the structural model of the foundation slab and the effect of the temperature (nonlinear analysis);

- Sensitivity study of the results against the main uncertainties in the structural model (probabilistic analysis and nonlinear analysis).

All the structural parameters and the design details mentioned in the previous items, together with the other aspects of the computational method, are briefly described in the following sections.

\section{Computational model}

4.1. Constitutive model for concrete

A smeared crack model has been chosen for the structural concrete. This model combines an elasto-plastic law with hardening in compression with an elasto-brittle model with softenjng in tension. The yield function $f\left(I_{1}, J_{2}\right)=\left[\alpha I_{1}+\beta\left(3 J_{2}\right)\right]^{1 / 2}=\sigma_{0}, \quad \alpha=0.355 \sigma_{0}$

\section{$\beta=1.355$}

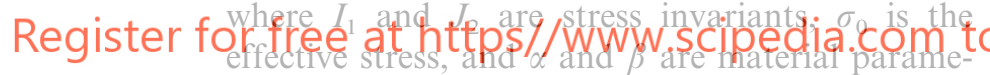
ters adjusted to fit the Kupfer tests (Kupfer et al., 1969) and do not depend on the actual concrete parameters such as the Young modulus, the Poisson ratio or compression/tension strengths.

Fig. 2 compares the yield function with Kupfer's experimental results.

For the compression criterion, the associate flow rule, according to standard plasticity theory (Lubliner, 1990), is:

$d \varepsilon_{i j}^{\mathrm{p}}=\mathrm{d} \lambda \frac{\partial f(\sigma)}{\partial \sigma_{i j}}=\mathrm{d} \lambda \boldsymbol{a}$

where $\mathrm{d} \lambda$ is the plastic multiplier and $\boldsymbol{a}=\partial f(\boldsymbol{\sigma}) /$ $\partial \sigma_{i j}$ is the normal to the actual load surface. From standard plasticity theory, it follows that $\mathrm{d} \lambda=\left(H^{\prime}+\boldsymbol{a}^{\mathrm{T}} \mathbf{D} a\right)^{-1} \boldsymbol{a} \mathbf{D} \mathrm{d} \boldsymbol{\varepsilon}$

where $H^{\prime}$ is the hardening parameter, $\mathbf{D}$ is the elastic constitutive matrix and $\mathrm{d} \boldsymbol{\varepsilon}$ is the total strain increment vector.

The complete incremental constitutive law is

$\mathrm{d} \sigma=\boldsymbol{D}_{\mathrm{ep}} \mathrm{d} \boldsymbol{\varepsilon} ; \quad \boldsymbol{D}_{\mathrm{ep}}=\mathbf{D}-\left(\mathbf{D} a a^{\mathrm{T}} \mathbf{D}\right)\left(H^{\prime}+\boldsymbol{a}^{\mathrm{T}} \mathbf{D} a\right)^{-1}$

where $\boldsymbol{D}_{\text {ep }}$ is the tangent elasto-plastic constitutive tensor. The hardening rule used is the parabolic curve

$\sigma=E_{0} \varepsilon\left(1-\frac{\varepsilon}{2 \varepsilon_{0}}\right)$

where $\sigma$ is the effective stress, $E_{0}$ is the initial Young modulus, $\varepsilon$ is the current total strain, and $\varepsilon_{0}$ the total strain corresponding to the peak compression stress $f_{\mathrm{c}}^{\prime}$. Given that $\varepsilon=\sigma / E_{0}+\varepsilon_{\mathrm{p}}$, it follows that

$\sigma=-E_{0} \varepsilon_{p}+\left(2 E_{0}^{2} \varepsilon_{0} \varepsilon_{\mathrm{p}}\right)^{1 / 2}, \quad c f_{\mathrm{c}}^{\prime}<\sigma_{0}<f_{\mathrm{c}}^{\prime}$

where $c f_{\mathrm{c}}^{\prime}$ is the elastic limit. By derivation

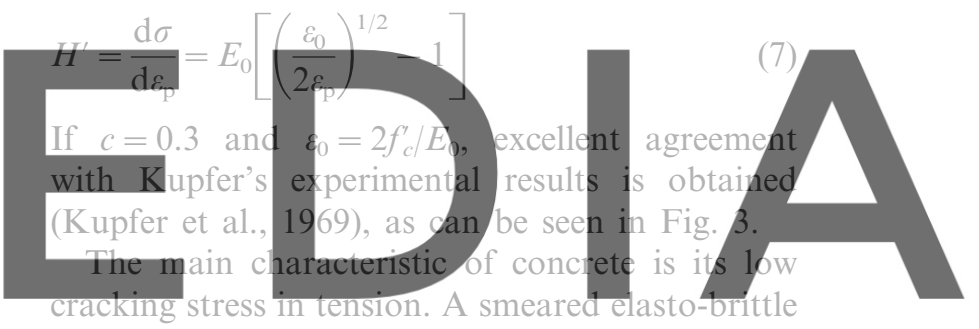

model is adopted herein, meaning that material

download the version without the watermark

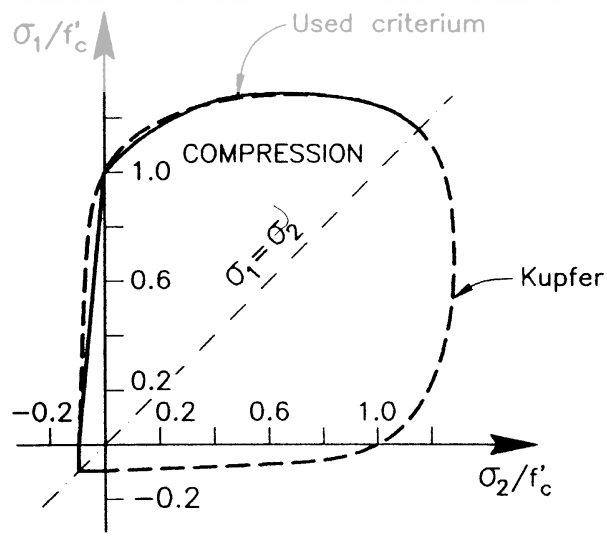

Fig. 2. Yield condition in compression and cracking in tension for concrete-biaxial stress state. 


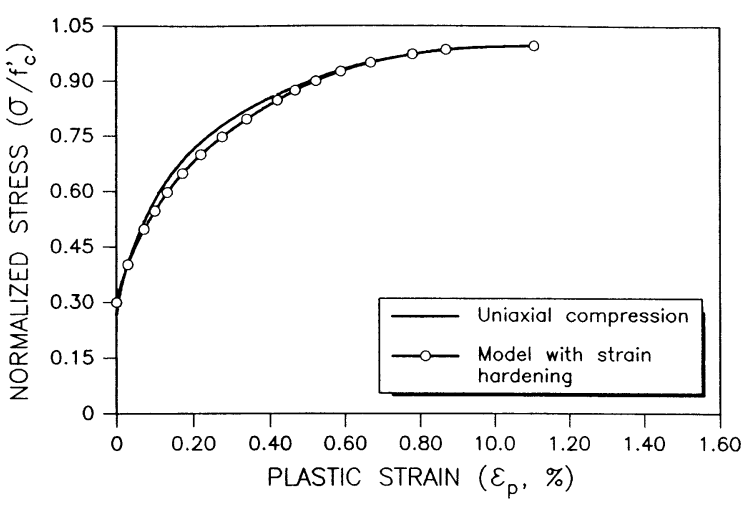

Fig. 3. Comparison between the hardening rule and Kupfer's uniaxial inelastic compression strains.

continuity is preserved even for cracked concrete regions.

The maximum tension principal stress is the cracking criterion, which is shown in Fig. 4. The crack appears when this stress exceeds the tension limit. The crack opens along the offending principal stress direction and the concrete becomes orthotropic. A maximum of two orthogonal cracks are allowed in each sampling point. Further details can be found in Cervera (1986), Ceryera et al. (1995b).

The post-cracking behaviour of concrete shows that even when cracked, the renaining strength can play an active role in structural stiffness, even if its influence degrades progressively, as can be seen in Fig. 5. The following degradation law has Register forefireent:https//www.scipedia.com to

$\sigma=f_{\mathrm{t}}^{\prime} \mathrm{e}^{-\left(\varepsilon-\varepsilon_{\mathrm{t}}\right) / \gamma} ; \quad \gamma=\frac{G_{\mathrm{f}}}{l_{\mathrm{c}} f_{\mathrm{t}}^{\prime}} ; \quad l_{\mathrm{c}}=(\mathrm{d} V)^{1 / 3}$

where $f_{\mathrm{t}}^{\prime}$ is the tension limit of concrete, $\varepsilon$ is the total strain in tension along the crack and $\varepsilon_{\mathrm{t}}$ is the same strain at the moment the crack occurs. An exponential softening law described by the parameter $\gamma$ is assumed. In Eq. (8), $G_{\mathrm{f}}$ is the fracture energy by unit area (a material property) and $l_{\mathrm{c}}$ is the characteristic length of the cracked finite domain $\mathrm{d} V$ (Lubliner et al., 1989).

The model allows for closing and reopening of cracks following a secant trajectory. Once completely closed, the stiffness normal to the crack is recovered.
The steps taken in order to consider all possible combinations of stress states are: (a) total strains, the corresponding elastic stress increments and total stresses are evaluated; (b) the previous existence or appearance of primary or secondary cracking is checked as a function of the actual strain-stress state, and the stress state is updated; (c) the existence of plastic behaviour is checked and internal variables and stresses are updated in consequence.

\subsection{Constitutive model for steel}

In this study, the reinforcement bars and the prestressed cables are assigned unidirectional stiffness properties. The liner is assumed biaxially isotropic. The constitutive behaviour is modelled by means of an elasto-plastic hardening law with elastic unloading. A strain limit corresponding to sudden failure is also considered.

\subsection{Description of the three-dimensional solid finite element}

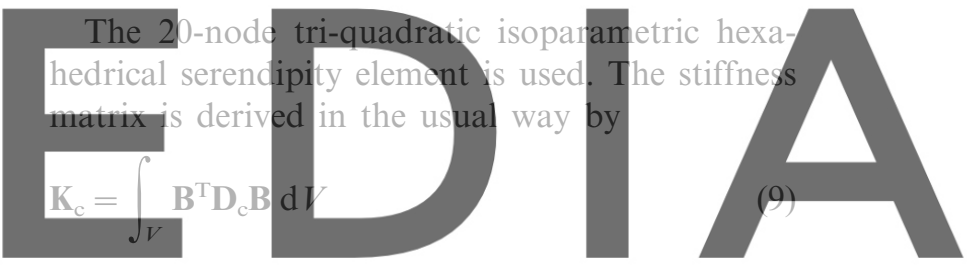

where $\mathbb{B}$ is the strain-displacement matrix, $\mathbb{D}_{c}$ is the material constitutive matrix for concrete and

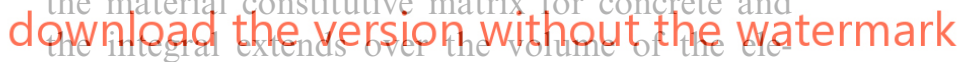
ment. The numerical integration is performed using a reduced quadrature of 15 integration points instead of the usual 27-point Gaussian quadrature, without losing accuracy and efficiency (Cervera and Hinton, 1986; Oñate, 1992). The rule is (see Fig. 6):

$$
\begin{aligned}
& \iiint_{-1}^{+1} f\left(\varepsilon_{1}, \varepsilon_{2}, \varepsilon_{3}\right) \mathrm{d} \varepsilon_{1} d \varepsilon_{2} d \varepsilon_{3} \\
& =A f(0,0,0)+B[f(-b, 0,0)+f(b, 0,0)+\cdots] \\
& \quad+C[f(-c,-c,-c)+f(-c,-c, c)+\cdots]
\end{aligned}
$$

where $\varepsilon_{1}, \varepsilon_{2}$ and $\varepsilon_{3}$ are the normalized natural coordinates. The weight factors and the sampling 


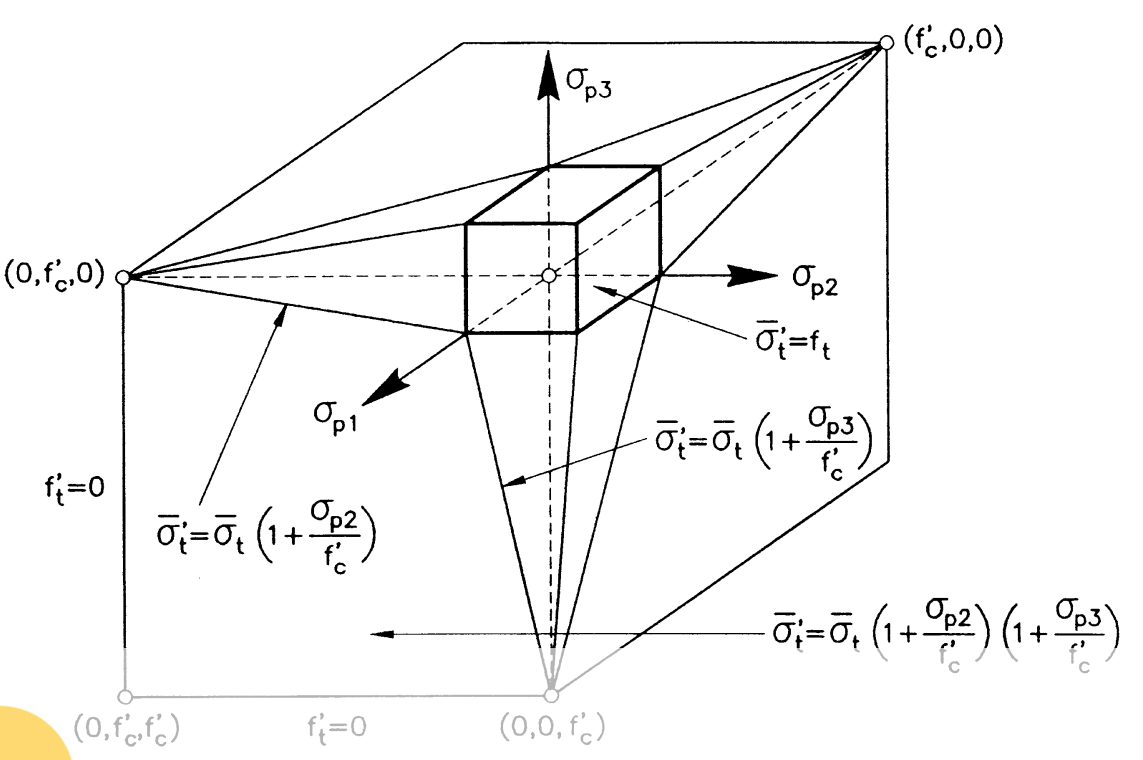

Fig. 4. Cracking surfaces for the concrete model, represented in the triaxial space of stresses.

points take the following values: $A=1.564444$, $B=0.3555556, C=0.5377778, b=1.000000$ and $c=0.6741000$. The position of these sampling points includes six points on the centre of the faces and one point in the centre of the element.

\subsection{Idealization of the passive reinforcement}

A perfect bond between the reinforcement bars and the surrounding concrete is assumed. This displacement compatibility allows treating the

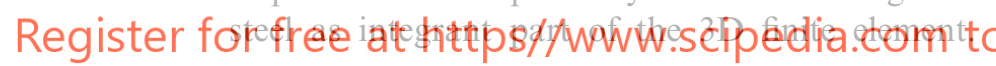

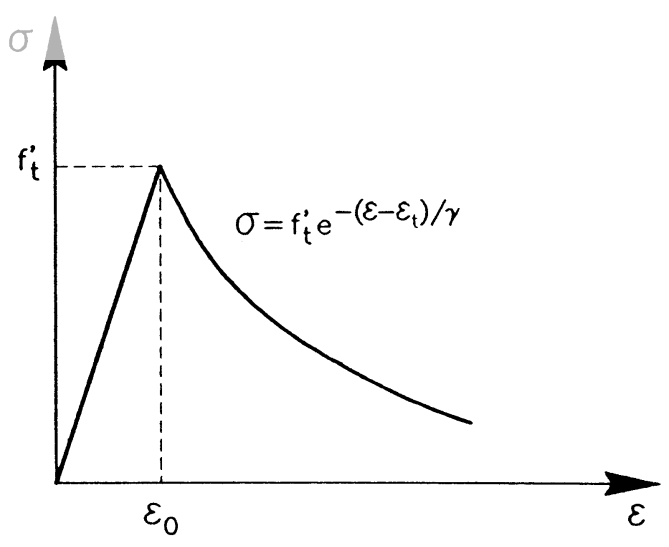

Fig. 5. Strain softening curve under tension.
The steel stiffness matrix, $\mathbf{K}_{\mathrm{s}}$, is added to that of the concrete, $\mathbf{K}_{\mathrm{c}}$, thus obtaining the total stiffness (see Fig. 7):

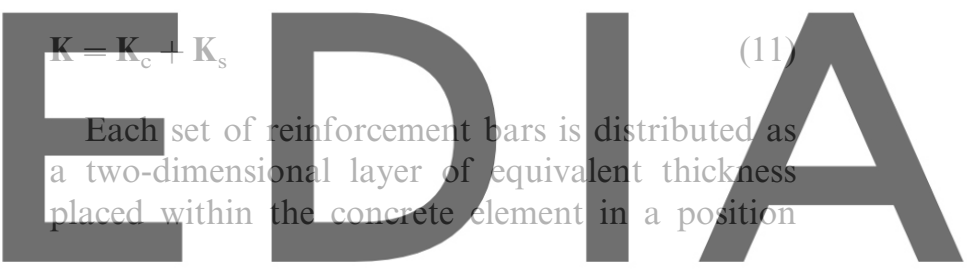

\section{$\varepsilon_{2}$}

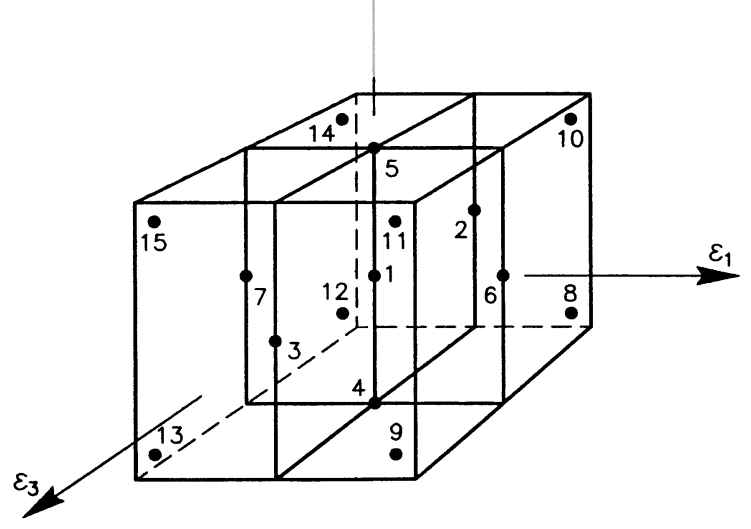

Fig. 6. Integration points distribution for the hexahedrical element. 


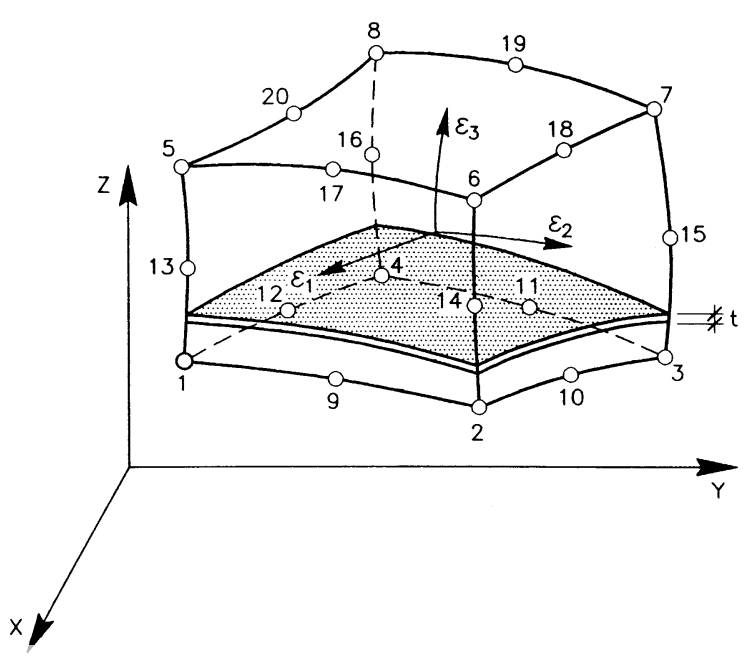

Fig. 7. Concrete element with a reinforcement steel layer. such that one of the local natural coordinates is constant for that layer. In that plane, the stiffness of the layer is oriented according to the direction of the actual bars.

The stiffness contribution of the steel is computed as follows:

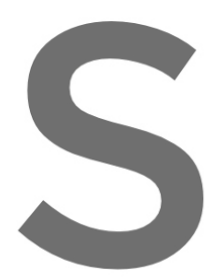

$\mathbb{K}_{\mathrm{s}}=\iint_{\Omega} \mathbb{B}^{\mathrm{T}} \mathbf{L}^{\mathrm{T}} \mathbf{D}_{\mathrm{s}} \mathbf{L} \mathbf{B} t \mathrm{~d}$

where $\mathbf{D}_{\mathrm{s}}$ is the constitutive matrix of the steel, $\mathbb{L}$ is the rotation matrix from the loeal coordinate system attached to the steel bar to the global

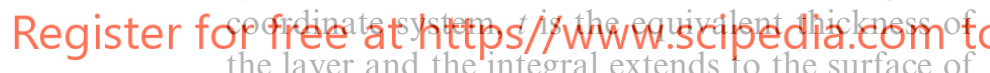
the layer,

The described element admits any number of layers, each made of different materials with uniaxial or biaxial behaviour.

\subsection{Idealization of the prestressing tendons}

The active reinforcement present in the structure studied consists of non-adherent tendons which have mainly two contributions to the overall structure stiffness: an active role due to the prestressing forces and a passive one due to their elongation during the deformation of the structure.
The active effect of the prestressing system is the most important in the evaluation of the failure pressure of the structure. It has been simulated by means of forces, equivalent to the prestressing ones, applied to the tendons and their effect is approximately equivalent to that of an exterior pressure which tends to compensate for the inner pressure produced by the accident. The value of the pressure at each point arises from the curvature of the cables, the friction with the concrete and the anchor system in the buttresses. Once applied to the structure, the system of equivalent prestressing forces is considered to be constant.

The passive effect of the prestressing system, that is, its contribution to the strength of the structure, is produced by the increase of the force in the tendons due to their elongation under actions subsequent to the installation. The internal pressure produces an elongation of all the tendon families of the structure and thus an increase of the prestressing forces and, consequently, an increment of the pressure applied by the tendons on the structure. In the case of the containment building studied, the circumferential

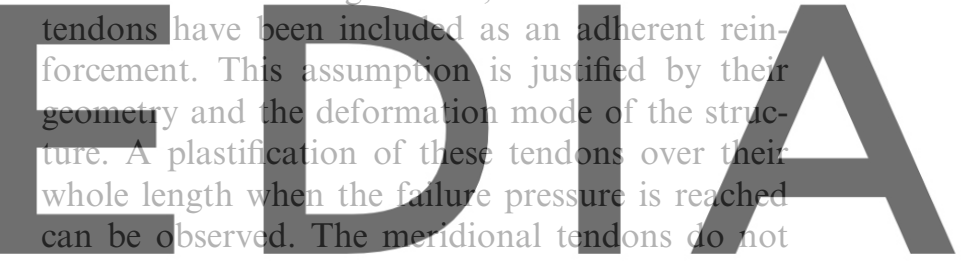

have a significant passive effect on the structural behaviour, as they are straight in the vertical dawinl gad the verisdonavithout the bNatermark as passive reinforcement.

\subsection{Computer program}

The finite element code STARC3 (Cervera et al., 1987a) was specifically developed for the analysis of reinforced concrete structures using the above described models. This computer program has been adapted for the analysis of the containment building of a large dry nuclear power plant. An incremental-iterative modified NewtonRaphson method with convergence accelerators is used to solve the nonlinear finite element equations. The program supplies not only detailed information on the ultimate load of the structure, 


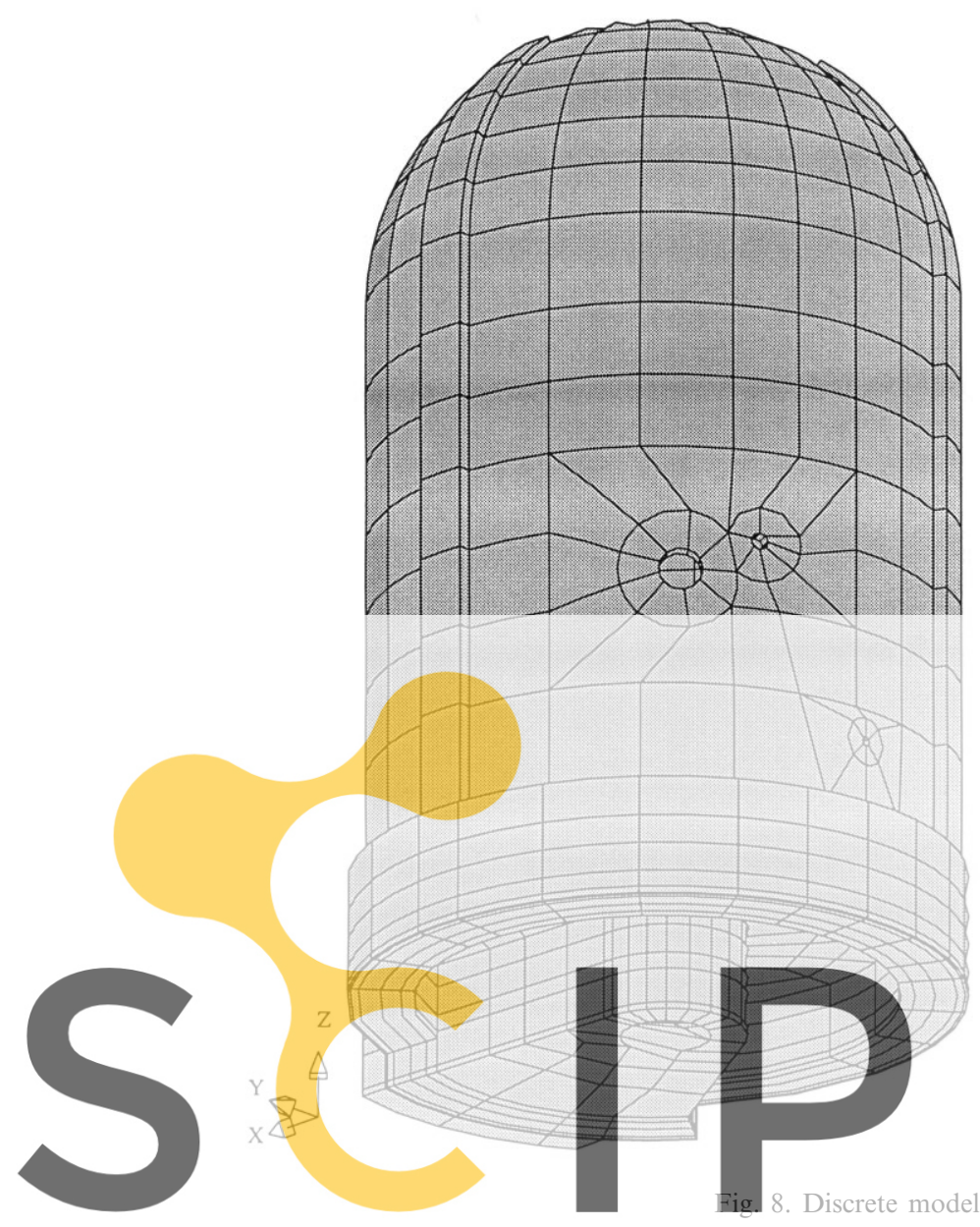

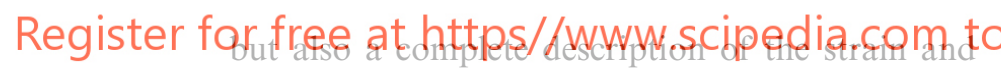
stress states for all the structural elements, the cracking state of the concrete and the yielding and failure of the active and passive reinforcement bars.

\section{Structural model and its calibration}

The 3D structural model used in this study has 1127 hexahedra and 7200 nodes (21600 degrees of freedom). Two views of the complete structural model can be seen in Fig. 8, where the foundation slab (together with the block of the reactor cavity), two buttresses, the personnel airlock, the fuel transfer penetration and the purge line penetra-

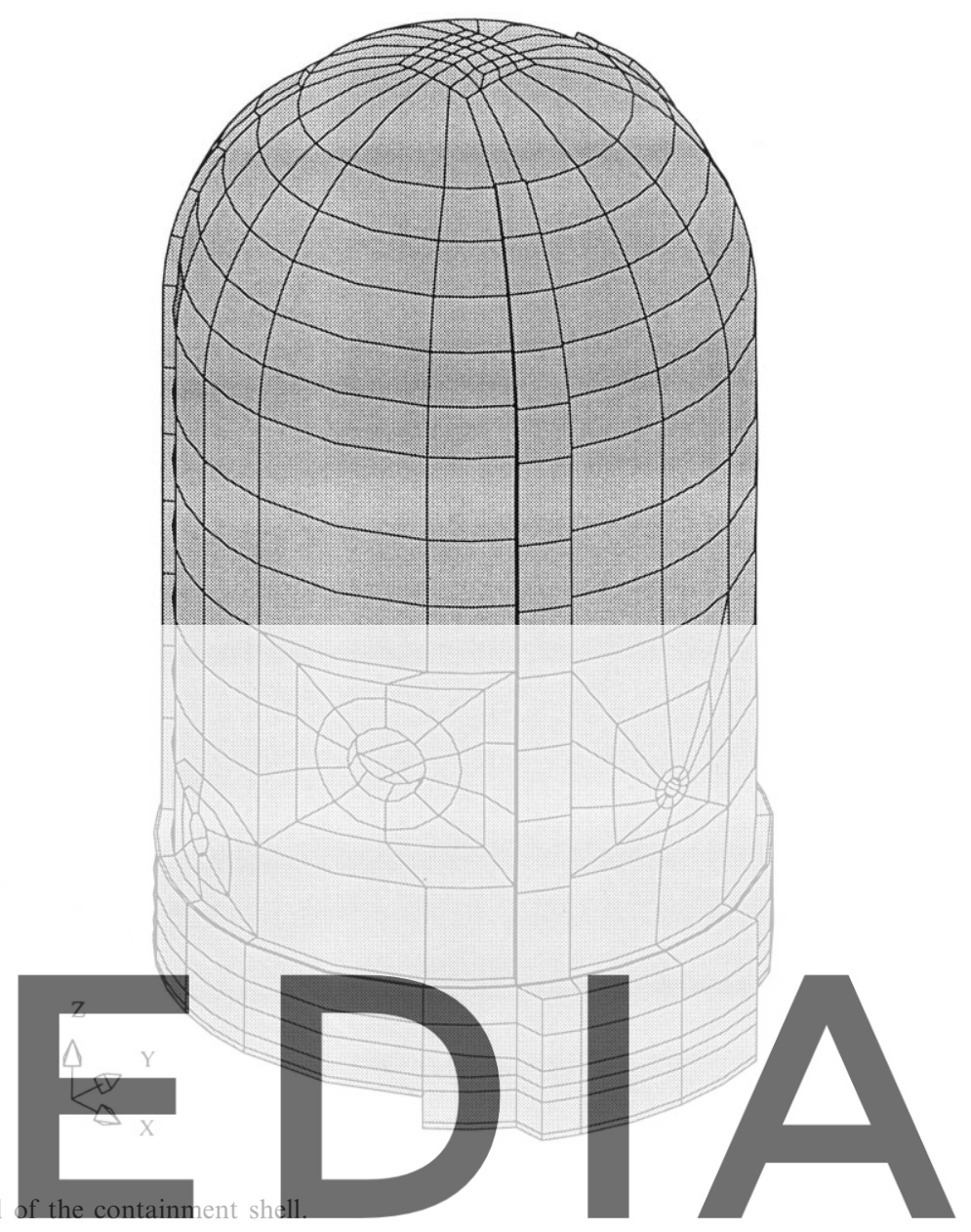

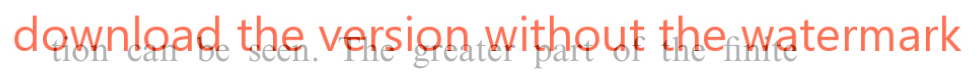
element mesh is used in the discretization of the foundation slab, for which, due to its geometrical and mechanical characteristics, the use of 710 elements with 4109 nodes (12327 degrees of freedom) was necessary. A total of 120 different layer systems had to be defined in the structural model to adequately describe the complex reinforcement and prestressing system of the complete structure (Cervera et al., 1995b).

The loads considered in the analysis were the self-weight, the external pressures generated by the prestressing system and the internal pressure corresponding to the specified accident. The distribution of the pressures equivalent to those produced by the prestressing system has been 


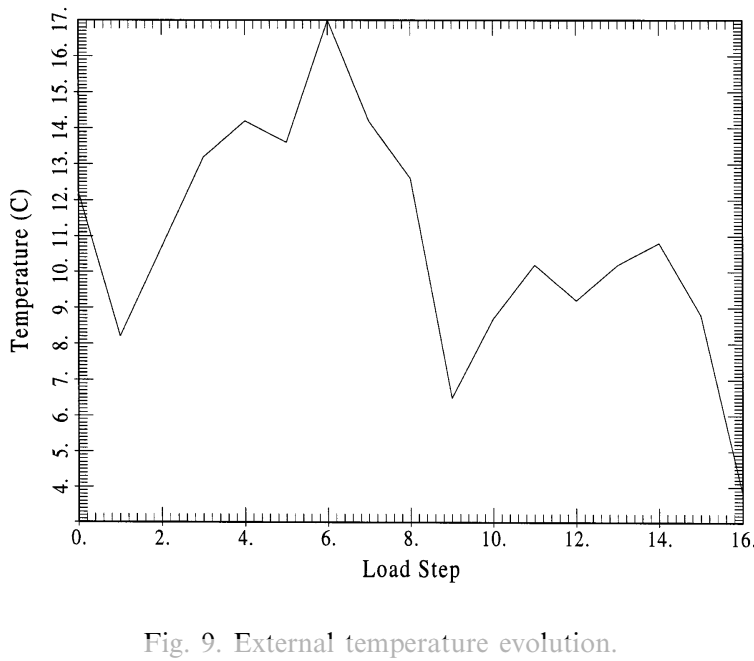

evaluated analytically for all the nodes of the mesh. All the possible sources of prestressing losses have been included in this evaluation, i.e., friction, wobble, anchor set, instantaneous and long term, etc. The internal pressure was increased gradually until the structural collapse occurred. The effect of the temperature gradient, according to the predefined accident sequence, was also included.

The model was calibrated using actual displacement and outside temperature measurements (Fig. 9) obtained during a 4-clay real pressurization experiment performed at the nuclear power plant studied. During the test, the inner pressure was

Register for free at https//www.scipedia.com to

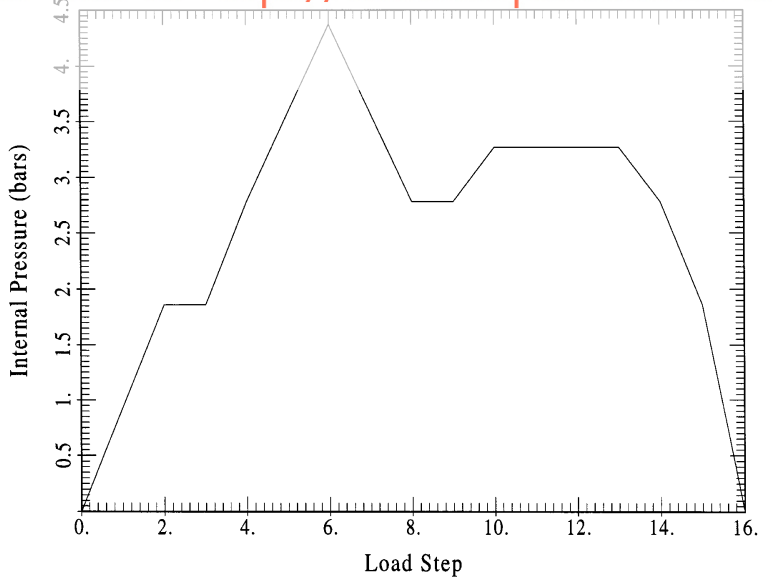

Fig. 10. Internal pressure evolution. increased up to 1.15 times the design pressure, which was $0.372 \mathrm{MPa}$ (see Fig. 10).

Some of the results of this simulation are shown in Figs. 11 and 12, for sensors placed in two different cross-sections of the containment building. A good agreement between the slopes of the experimental and simulated curves can be seen, which demonstrates that the finite element model describes adequately the stiffness of the real structure. The results of the test mentioned allowed the calibration of those parameters of the model referring to the amount of reinforcement steel to be included in the regions where unconsidered penetrations exist. It was a safe way to determine how much of the actual reinforcement is needed to make up for the loss of wall stiffness due to the penetrations.

\section{Deterministic evaluation of the failure pressure}

The influence of the inclusion of the foundation slab in the structural model on the global structural behaviour and especially on the failure pres-

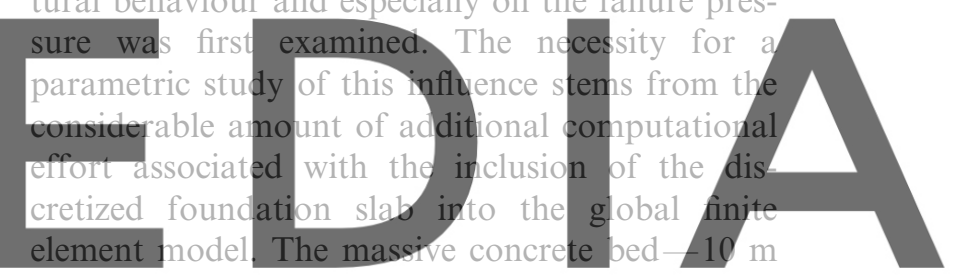

thick - on which the foundation slab is supported

was approximated by means of a unique finite

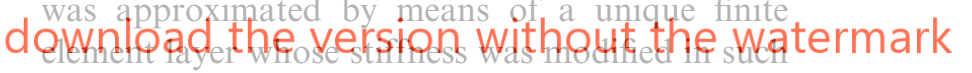

a way that it simulated the real stiffness of the concrete bed. A low tensile strength was assumed in order to allow the slab to move upwards almost independently (Barbat et al., 1995). The results show that the influence of including the slab is small for low levels of internal pressure; in addition, it decreases further as the pressure increases and it is negligible near the failure pressure, which is $1.11 \mathrm{MPa}$ in both cases. Furthermore, the cylindrical wall behaves better when the slab is present, due to the fact that the displacements of the slab slightly reduce the circumferential displacements of the wall; this allows to conclude that by not including the slab, one stays on the safety side during the complete load 

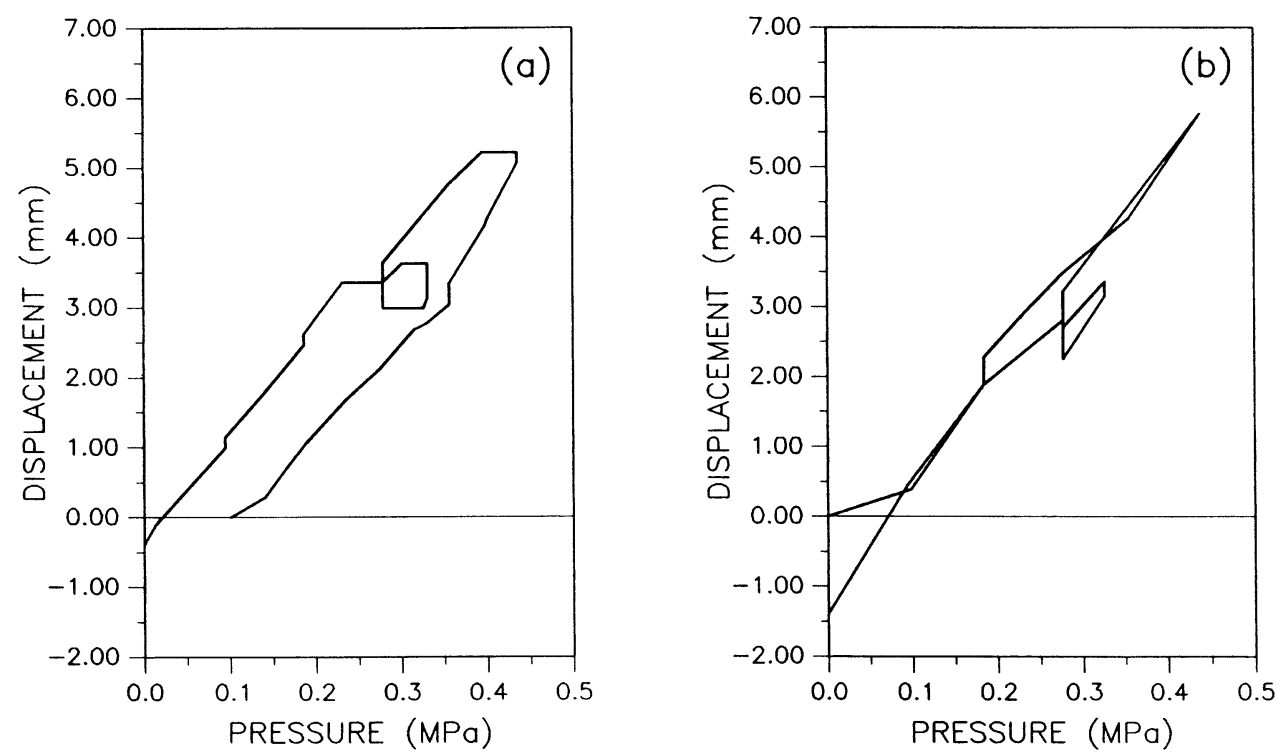

Fig. 11. (a) Experimental results and (b) numerical results for the pressurization test, sensor placed in the $0^{\circ}-180^{\circ}$ cross-section.

history. The comparison was based on an extensive survey of displacements, cracking patterns and reinforcement stresses along the load path. This conclusion was useful to reduce the computational effort required by the Monte Carlo simulation performed during the probabilistic evaluation of the failure pressure.

In Fig. 13 a comparison is made of the radial displacement-pressure curves for the models with and without foundation slab, corresponding to the same point of the structure at the cylinder midheight, where maximum displacement occurs. The different response over $0.7 \mathrm{MPa}$ is due to the fact that cracking appears at the slab-wall junction, thus softening the clamping effect at the wall in the model which includes the foundation slab. This difference does not affect the failure pressure, and only slightly alters the failure displacements.

The effect of the temperature was also studied, comparing the behaviour of the structure subjected to the same internal pressure history, with and without thermal gradient in its walls. The transient temperature regime was calculated by simulating an accident sequence for the nuclear power plant and the resulting internal temperature and pressure curves are those given in Figs. 14 and 15. It came out that the increase of internal temperature produces a slight increase of the failure pressure of the containment building, up to 1.25 MPa, due to the net compression effect that the temperature induces in the wall. This is due to the restraining of the thermal strains produced by the stiffness of the buttresses. The compression effect reduces the tension in part of the reinforcement of the vertical wall and this results in a slight increase of the failure pressure. Fig. 16 shows a comparison between the pressure-radial displacement curves for the cases when the thermal effects are considered and when they are neglected; both curves correspond to the same point of the structure, namely the one where maximum displacements occur.

Figs. 17 and 18 show results of a typical simulation of the behaviour of the structure under increasing internal pressure until failure. Fig. 17 shows the deformed shape of the structure in horizontal and vertical views (the magnification factor for the displacements is 30): (a) and (c) correspond to a pressure of $1.05 \mathrm{MPa}$, while (b) and (d) correspond to the failure pressure of 1.11 $\mathrm{MPa}$. It can be seen that between these two pressures the structure undergoes severe damage and loss of resistance, as displacements grow largely in this interval, with change in the deformation mode. 

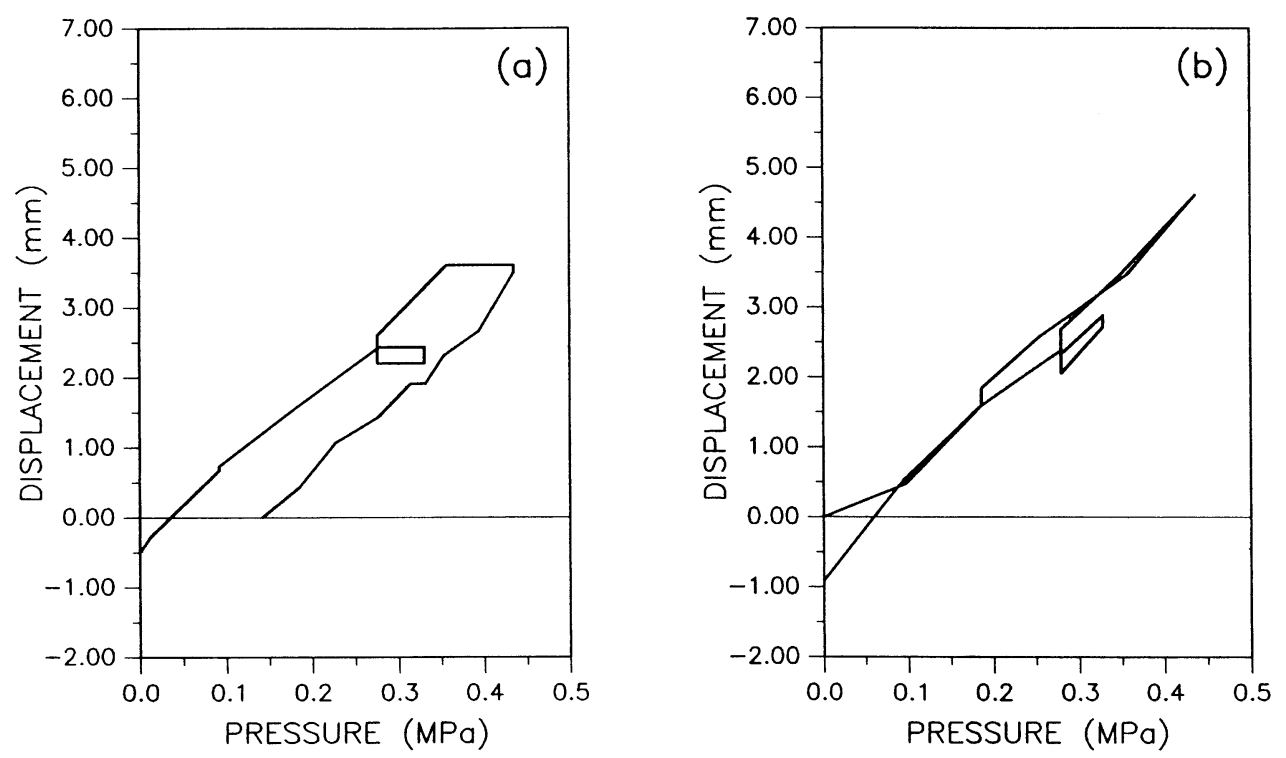

Fig. 12. (a) Experimental results and (b) numerical results for the pressurization test, sensor placed in the $90^{\circ}-270^{\circ}$ cross-section.

Fig. 18(a)-(c) shows the evolution of cracking for pressures of $1.07,1.09$ and $1.11 \mathrm{MPa}$, respectively. The arrows indicate the normal to the plane of the cracks. Only the cracks corresponding to a strain level higher than $0.5 \%$ have been represented. Fig. 18(d) shows the broken reinforcement bars at the moment of failure, corresponding to strains higher than $0.8 \%$. The arrows

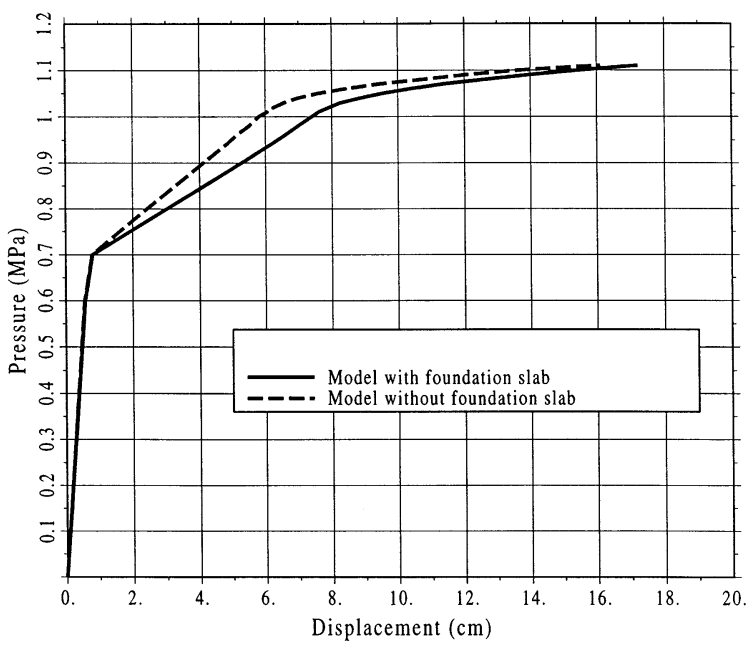

Fig. 13. Pressure-radial displacement curves for the point with maximum displacements in the failure zone, structural model with and without foundation slab. in (d) indicate the direction of the broken reinforcement bars. The model used in the analysis demonstrates an important capacity to localize the deformation when the damage sets in. Once cracking diminishes the stiffness of concrete, the reinforcement is the only element to withstand the pressure. Hence, the ultimate state depends almost entirely on the amount of steel and its properties. This reduces heavily the impact of the concrete and therefore of its constitutive behaviour on the failure pressure of the containment, and suggests that its complexity may be kept at a minimum.

The analysis of the effect of the foundation slab on the overall behaviour of the structure is completed with a global damage index (GDI) study. This consists in examining the evolution of several critical structural parts throughout the loading process. The global damage index formulation employed here is the result of a rigorous theoretical framework applicable to any constitutive material law (Hanganu, 1997). Its general form is (Barbat et al., 1997)

$$
D=1-\frac{\Sigma_{e} \boldsymbol{a}^{\mathrm{T}} \int_{V^{(e)}} \boldsymbol{B}^{\mathrm{T}} \boldsymbol{\sigma} \mathrm{d} V}{\Sigma_{e} \boldsymbol{a}^{\mathrm{T}} \int_{V^{(e)}} \boldsymbol{B}^{\mathrm{T}} \boldsymbol{\sigma}^{0} \mathrm{~d} V}
$$




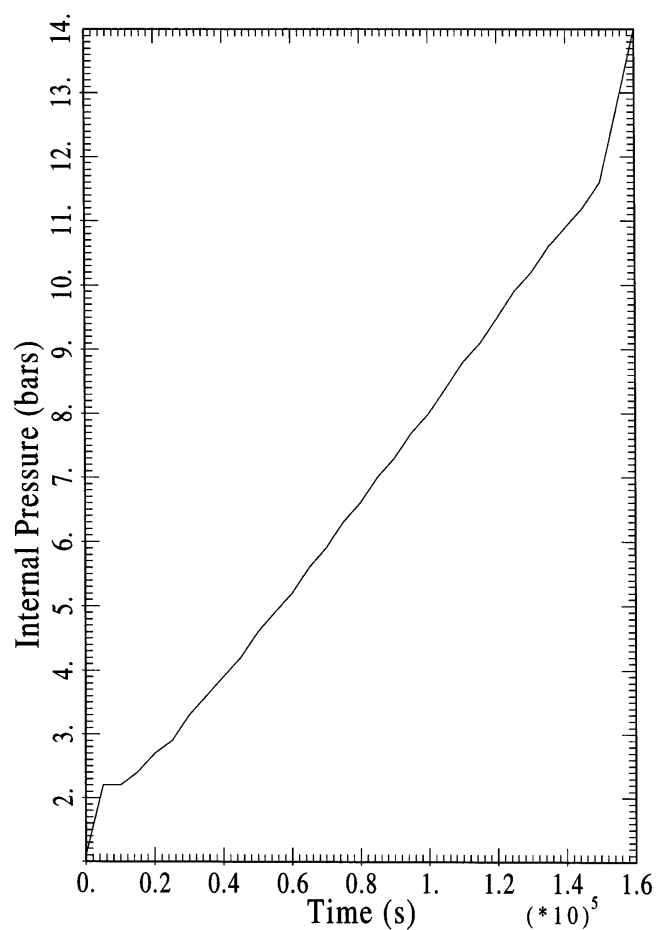

Fig. 14. Temperature-time curve for a simulated accident.

where $\Sigma_{e}$ denotes the sum operator over finite elements, $\boldsymbol{a}$ is the elemental displacement vector, $V^{(e)}$ is the volume of finite element $(e), \sigma$ is the actual stress vector and $\sigma^{0}$ is the stress vector should the material preserve its original characteristics.

This GDI evaluation may be applied to the whole structure and/or to parts of it by altering the range of the above sum operator. It is obvious that no algebraic relation may be driven between the GDI of a structure and the GDIs of its parts. The smallest entity on which a GDI may be calculated is one finite element.

A GDI value has the significance of the ratio between the potential energy the structure cannot undertake as a result of damage and the potential energy the structure would store had it stayed undamaged.

Fig. 19 (model without slab) and Fig. 20 (model with slab) present the evolution of several GDIs belonging to the most representative (from a failure pressure point of view) zones of the structure. Given that the failure occurs at mid-cylinder, the

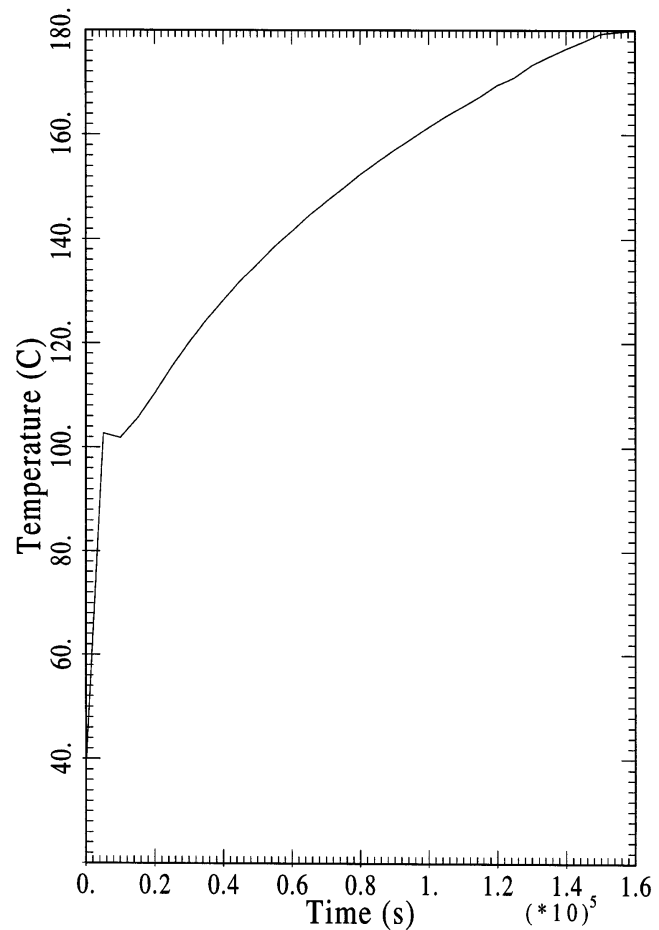

Fig. 15. Internal pressure-time curve for a simulated accident.

cylinder was divided in three disjoint rings of finite elements, thus: the first ring is made of the inferior row of elements which do the joint with

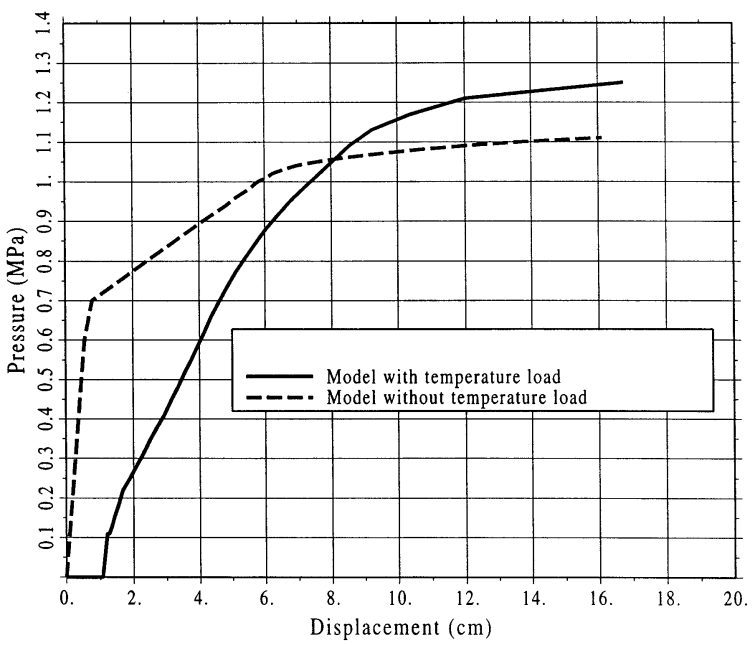

Fig. 16. Pressure-radial displacement curves for the point with maximum displacements in the failure zone, with and without thermal effects. 


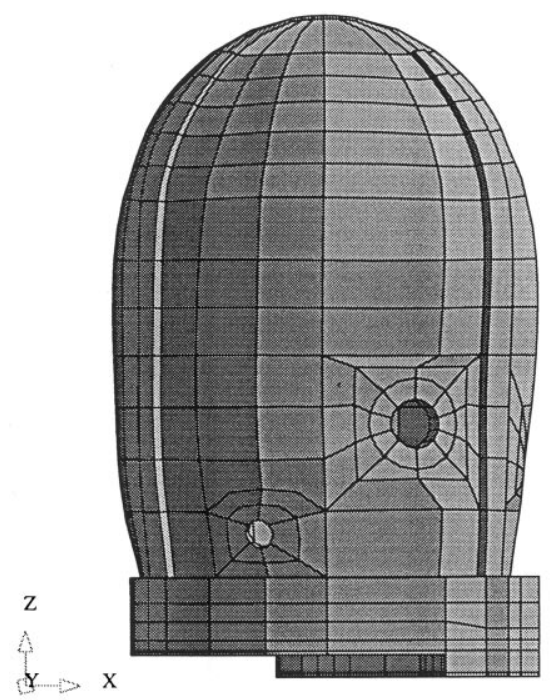

(a)
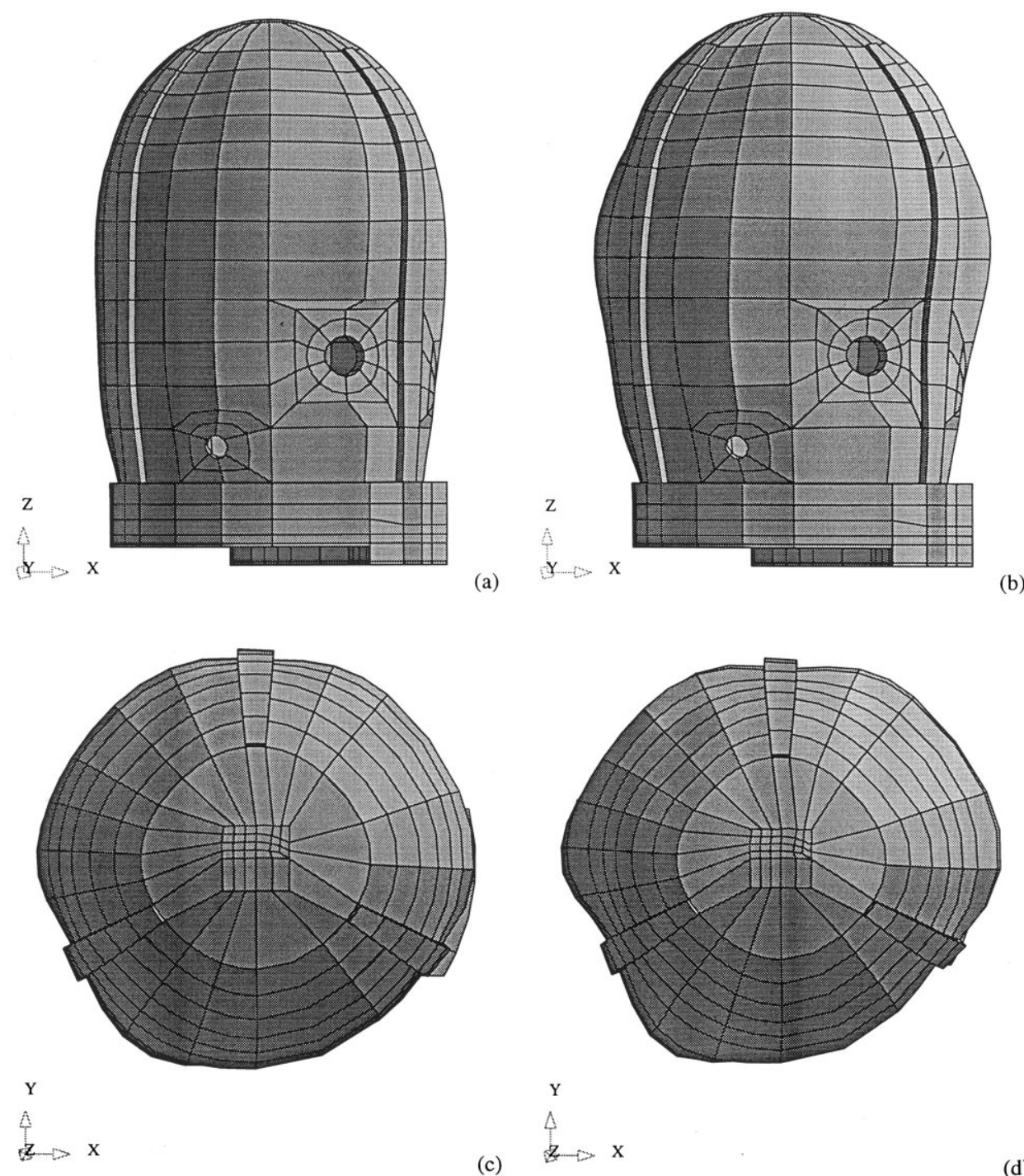

(b)

(c)

(d)

Fig. 17. Deformed shape of the structure for internal pressures of $1.05 \mathrm{MPa}$ ((a) and (c)) and $1.11 \mathrm{MPa}$ ((b) and (d)). The magnification factor for the displacements is 30 .

the slab, the second ring contains the following three rows, and the last three rows ending where the dome begins belong to the third ring. Separately, GDIs for the cylinder as a whole, the dome, the slab and the entire structure were also calculated. In both figures, zooms of the final instants are given in order to show in detail what happens just before structural failure.

The first observation is that the GDIs have an almost identical behaviour in the two cases, which confirms that the presence of the foundation slab does not influence the overall degradation patterns which develop at mid-cylinder. The overall GDI and the GDIs for cylinder, the second and third rings take very close values, which means the overall damage takes into account exclusively what happens in those rings and what happens with the rest of the structure has little relevance. The final proof is that although the slab GDI displays important variations and finally takes 


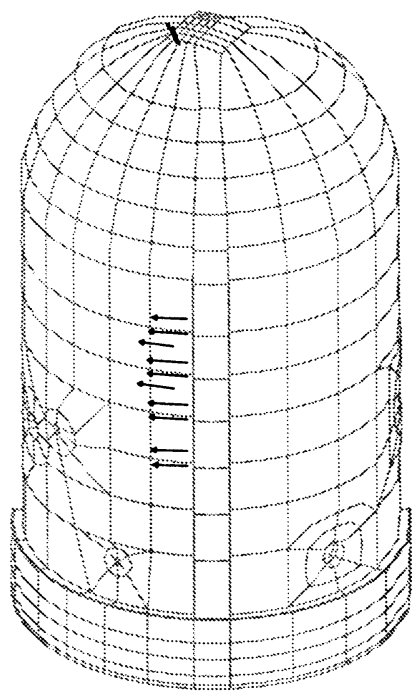

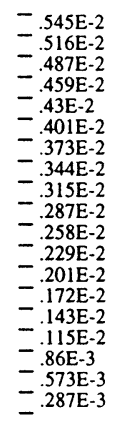

(a)

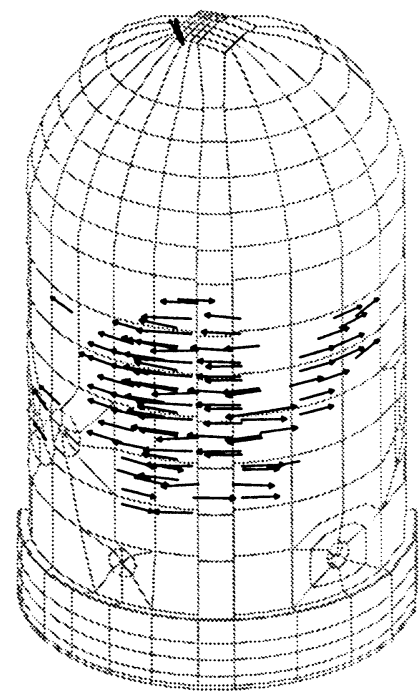

$=.776 \mathrm{E}-2$
$=.736 \mathrm{E}-2$
$=.695 \mathrm{E}-2$
$=.654 \mathrm{E}-2$
$=.613 \mathrm{E}-2$
$=.572 \mathrm{E}-2$
$=.531 \mathrm{E}-2$
$=.49 \mathrm{E}-2$
$=.45 \mathrm{E}-2$
$=.409 \mathrm{E}-2$
$=.368 \mathrm{E}-2$
$=.327 \mathrm{E}-2$
$=.286 \mathrm{E}-2$
$=.245 \mathrm{E}-2$
$=.204 \mathrm{E}-2$
$=.163 \mathrm{E}-2$
$=.123 \mathrm{E}-2$
$=.817 \mathrm{E}-3$
$=.409 \mathrm{E}-3$

(b)

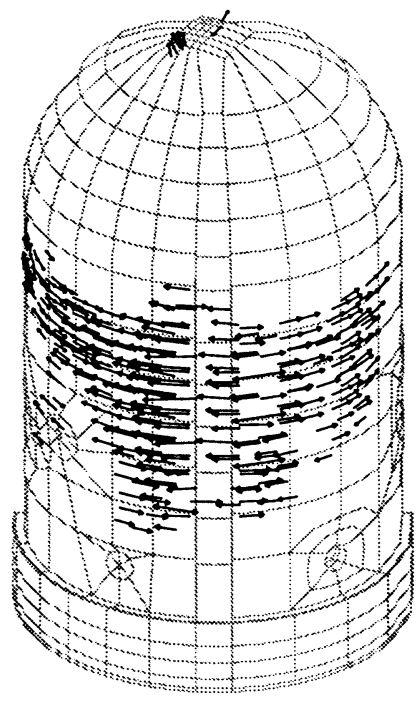

$=.135 \mathrm{E}-1$
$=.128 \mathrm{E}-1$
$=.121 \mathrm{E}-1$
$=.114 \mathrm{E}-1$
$=.107 \mathrm{E}-1$
$=.996 \mathrm{E}-2$
$=.925 \mathrm{E}-2$
$=.854 \mathrm{E}-2$
$=.782 \mathrm{E}-2$
$=.711 \mathrm{E}-2$
$=.64 \mathrm{E}-2$
$=.569 \mathrm{E}-2$
$=.498 \mathrm{E}-2$
$=.427 \mathrm{E}-2$
$=.356 \mathrm{E}-2$
$=.285 \mathrm{E}-2$
$=.213 \mathrm{E}-2$
$=.142 \mathrm{E}-2$
$=.711 \mathrm{E}-3$

(c)

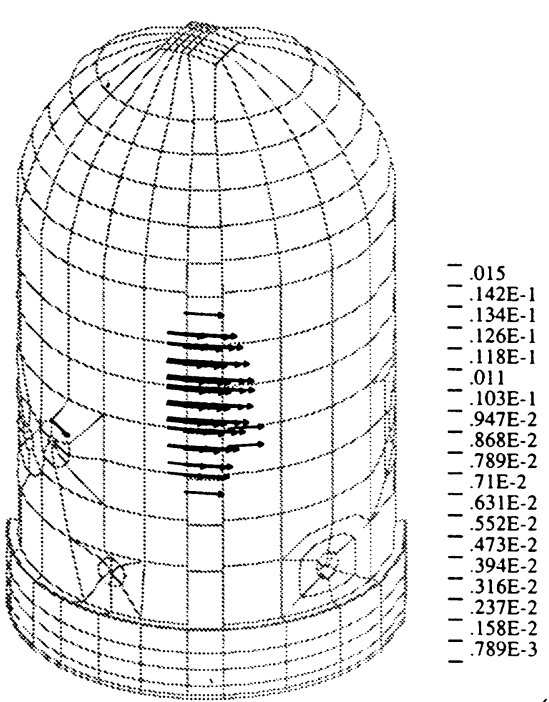

(d)

Fig. 18. Crack patterns for internal pressures of (a) $0.6 \mathrm{MPa}$, (b) $0.7 \mathrm{MPa}$ and (c) $0.8 \mathrm{MPa}$. In (d), the broken reinforcement bars can be seen.

values well above the overall GDI, this last is never influenced by the state of the slab and the driving influence remains that of the above-mentioned rings. The states of the first ring or the dome have little effect, while the cylinder GDI at its turn behaves like the overall GDI.

This behaviour is in line with the known prop- erties of this GDI method (Hanganu, 1997) to 'filter out' the irrelevant parts of the structure, and to identify and follow the evolution of its critical zones. The fact that the overall GDI reaches in both cases close to the unit show that the structure really fails when the pressure reaches 11.1 bars. 


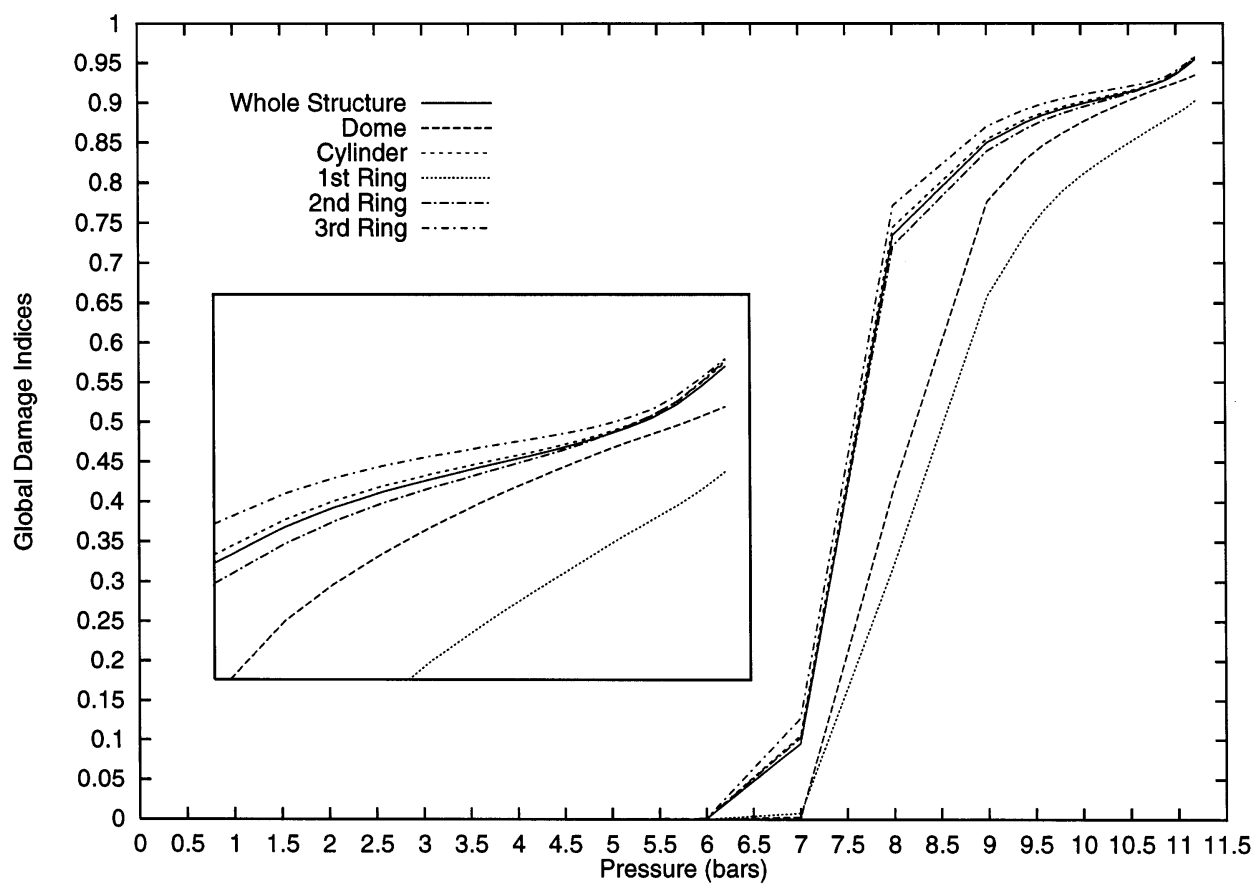

Fig. 19. Evolution of global damage indices of representative structural parts for the model without foundation slab (zoom of the final part in the box).

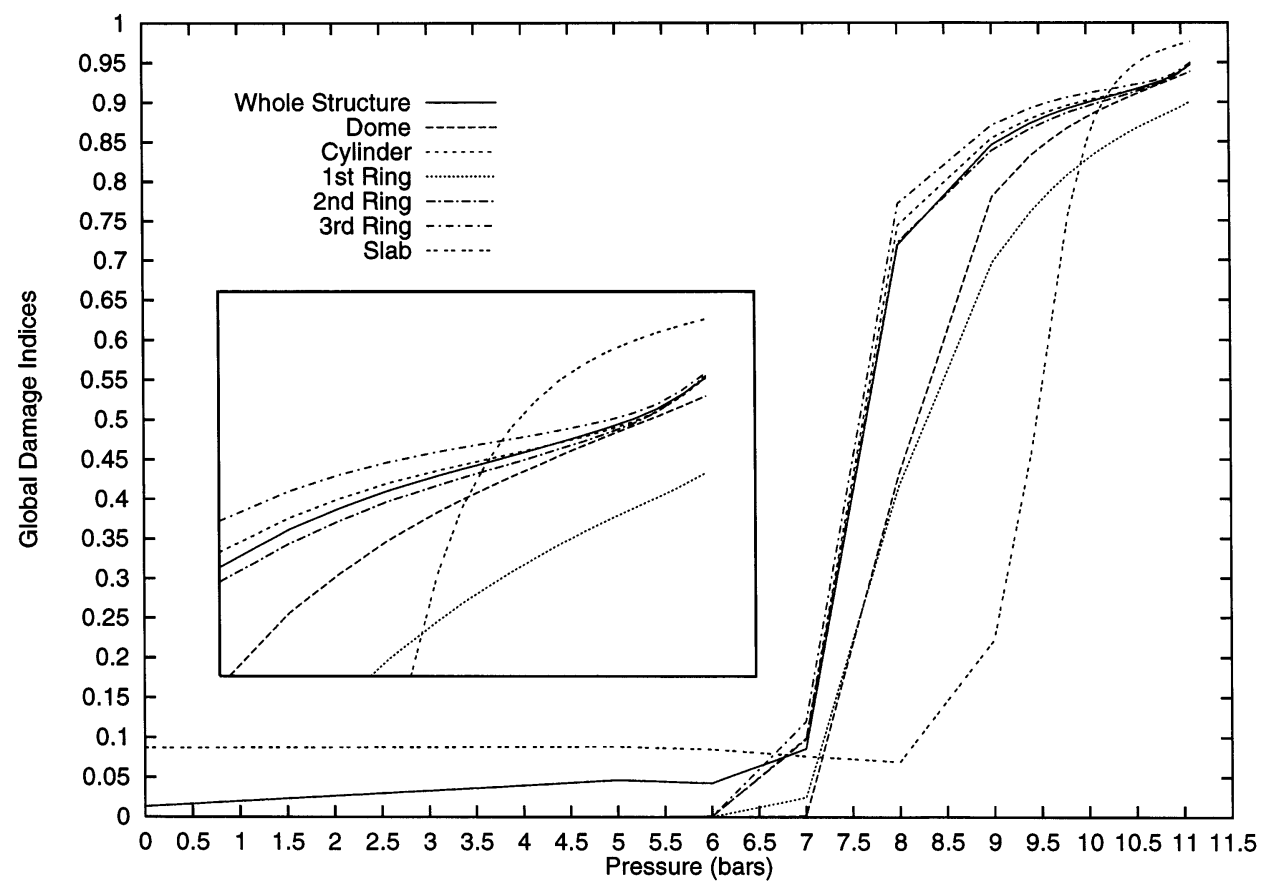

Fig. 20. Evolution of global damage indices of representative structural parts for the model with foundation slab (zoom of the final part in the box). 


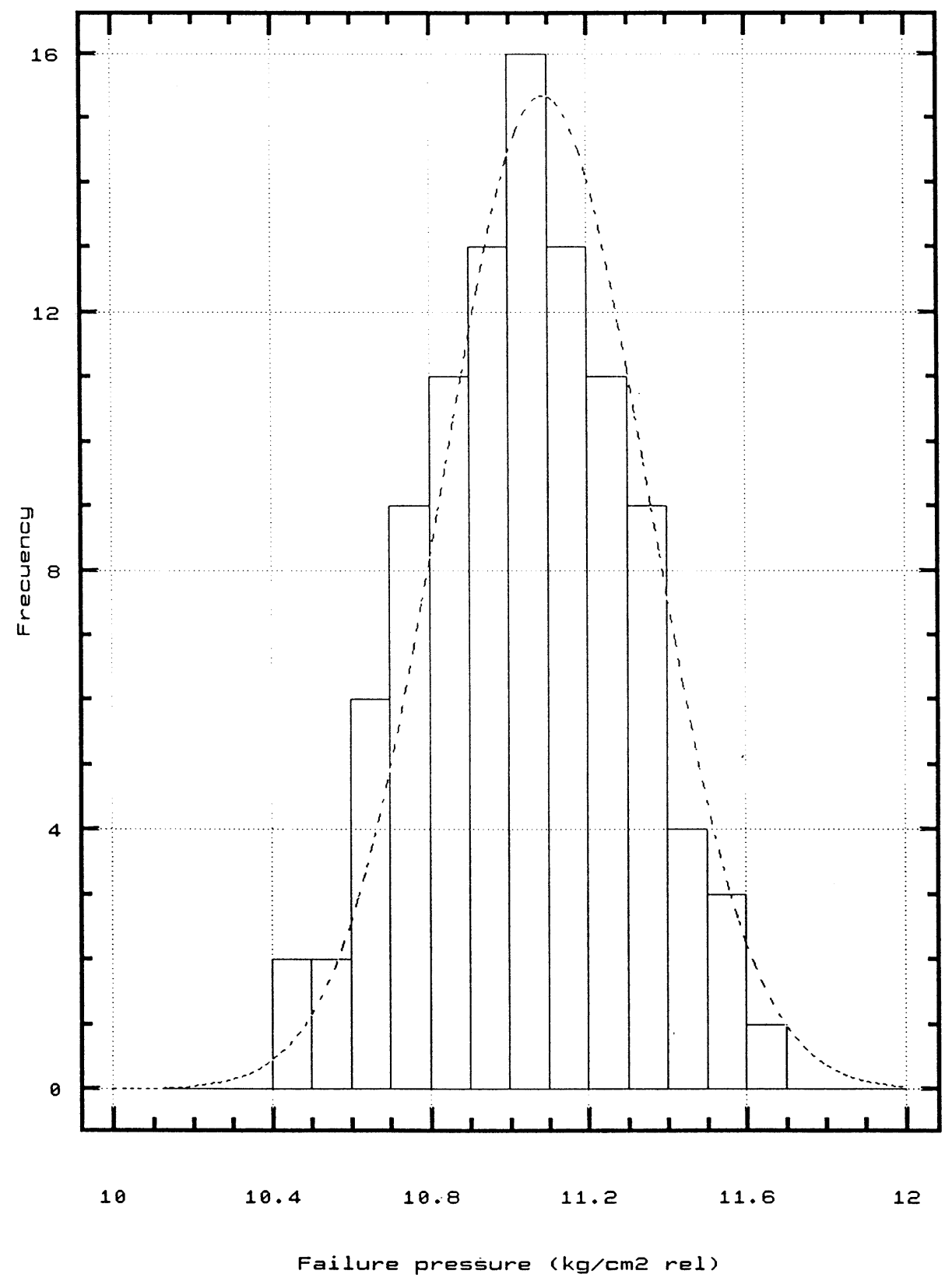

Fig. 21. Histogram corresponding to the 100 numerical simulations of the failure pressure and the corresponding probability density curve.

\section{Probabilistic study of the failure pressure}

The aim of the probabilistic analysis was to determine the structural fragility curve of the containment building of the large dry nuclear plant. This curve gives the failure probability as a function of the internal pressure and it is the integral of the probabilistic density function of the failure pressure. Due to the uncertainties in material properties and in the prestressing system 


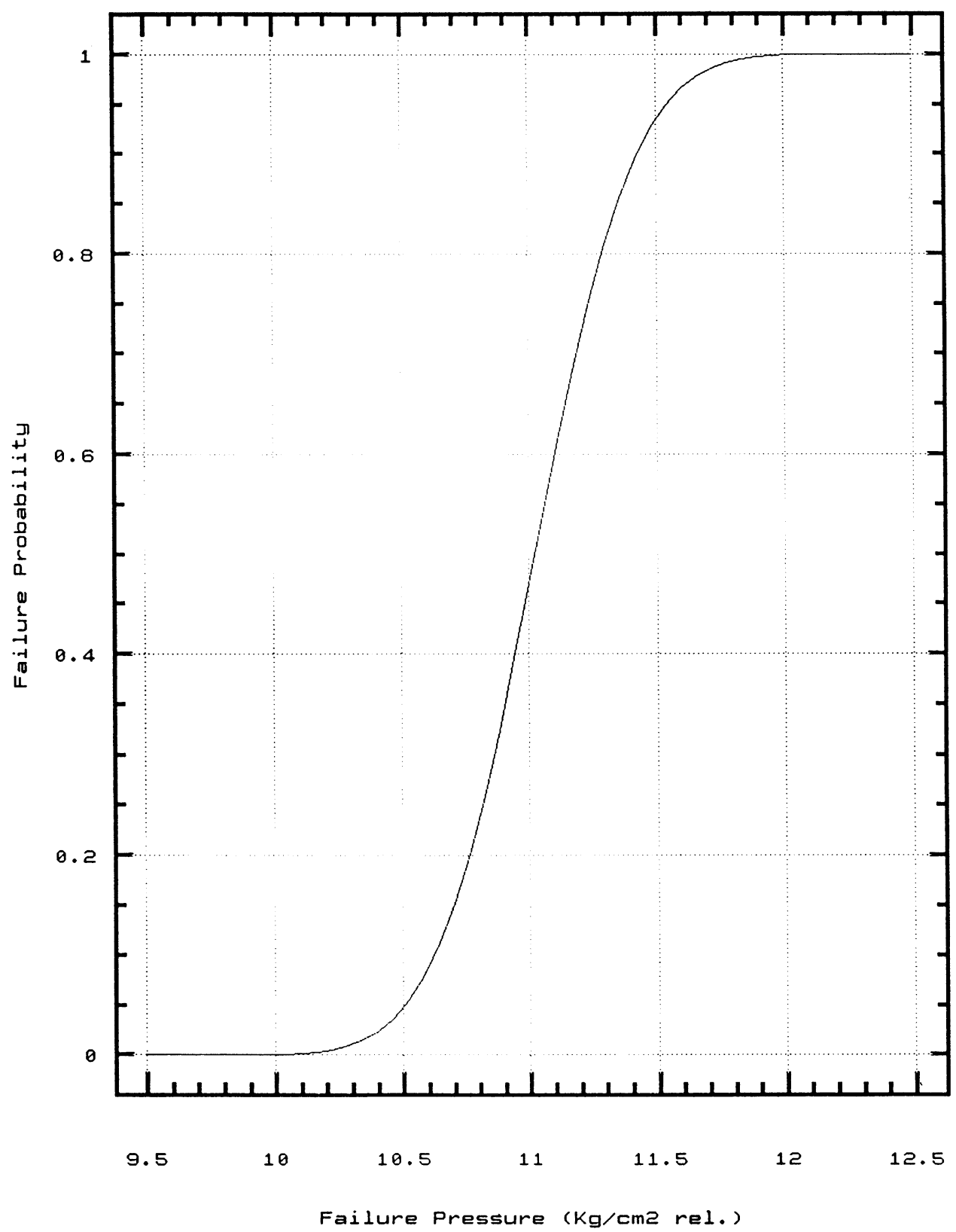

Fig. 22. Fragility curve.

parameters, a Monte Carlo process is used to calculate the fragility curve (Rubinstein, 1981). Eighteen parameters, 14 of them related to prestressing (Young's modulus, equivalent surface of the cross-section, yielding stress, hardening parameter, prestressing forces and prestressing losses, for the different tendon families), three related to reinforcement steel (Young's modulus, yielding stress and hardening parameter) and one related to concrete (Young's modulus), were considered. Mean values, standard deviations and probability distributions were assigned to each 
parameter in base of available test data. Then, 100 sets of data were simulated, by generating random values for each variable according to the above mentioned distributions. By using the computer program STARC3, 100 failure pressure values were obtained in a deterministic way and organized in the histogram of Fig. 21, where the probability density curve is also given. By integrating the probability density curve, the fragility curve shown in Fig. 22 is obtained.

On the basis of this fragility curve, the failure pressure corresponding to a $5 \%$ probability of failure is obtained, with a value of $1.05 \mathrm{MPa}$. This gives a safety coefficient of 2.78 with respect to the design pressure, which lies within the range given by other studies.

\section{Conclusions}

This paper has described a study of the failure pressure for the containment building of a large dry nuclear power plant, for an accident scenario beyond the design one. The method used in the evaluation of the failure pressure is based on computer simulation of the complete damage process of the containment building, by means of a fully three-dimensional nonlinear finite element model. The model includes the most relevant structural aspects required in an accurate numerical simulation. The results obtained demonstrate that the influence of the foundation slab and of the thermal loads can be safely neglected in the failure pressure analysis of a structure of this type. The failure mechanism corresponds to the failure of the circumferential reinforcement bars of the mid-cylinder ring of the wall, leading to a wide vertical crack in the structure near to one of the buttresses. The probabilistic study provides the fragility curve of the structure. The failure pressure obtained for a failure probability of $5 \%$ is 1.05 $\mathrm{MPa}$, the safety coefficient of the structure related to the design pressure being 2.78 .

\section{Acknowledgements}

This work has been financially supported by Central Nuclear Vandellós.

\section{References}

ASCE Committee on Concrete and Masonry Structures, 1982. State-of-the-art report on finite element analysis of reinforced concrete. Task Committee on Finite Element Analysis of Reinforced Concrete Structures, ASCE Special Publication.

Barbat, A.H., Cervera, M., Hanganu, A., Cirauqui, C., Oñate, E., 1995. Evaluación de la presión de fallo del edificio de contención de una central nuclear tipo PWR-W tres lazos. Parte II: simulación numérica. Rev. Int. Métodos Numéricos para Cálculo y Diseño en Ingeniería 11 (3), 451-475.

Barbat, A.H., Oller, S., Oñate, E., Hanganu, A., 1997. Viscous damage model for Timoshenko beam structures. Int. J. Solids Struct. 34 (30), 3953-3976.

Bićanić, N., Mang, H.A. (Eds.), 1990. Computer Aided Analysis and Design of Concrete Structures. Proc. SCI-C II Int. Conf., Pineridge Press, Swansea, UK.

Cervera, M., 1986. Nonlinear analysis of reinforced concrete structures using three dimensional and shell finite element models. Ph.D. Thesis, University of Wales, Swansea, UK.

Cervera, M., Hinton, E., 1986. Nonlinear analysis of reinforced concrete plates and shells using a three dimensional model. In: Hinton, E., Owen, R. (Eds.), Computational Modelling of Reinforced Concrete Structures. Pineridge Press, Swansea, UK, pp. 327-370.

Cervera, M., Hinton, E., Hassan, O., 1987a. Nonlinear analysis of reinforced concrete plate and shell structures using 20-noded isoparametric brick elements. Comput. Struct. 25 (6), 845-869.

Cervera, M., Hinton, E., Bićanić, N., 1987b. Nonlinear transient dynamic analysis of three dimensional reinforced concrete structures using a three-dimensional approach. In: Lewis, R.W., Hinton, E., Bettess, P., Schrefler, B.A. (Eds.), Numerical Methods in Transient and Coupled Problems. Wiley, New York, pp. 279-318.

Cervera, M., Oliver, J., Oñate, E., Herrero, E., 1990. A computational model for progressive cracking in large dams due to the swelling of concrete. Eng. Fract. Mech. 35 (1-3), 573-585.

Cervera, M., Oliver, J., Galindo, M., 1992. Numerical analysis of dams with extensive cracking due to concrete hydration: simulation of a real case. Dam Eng. 3 (1), 1-22.

Cervera, M., Oliver, J., Faria, R., 1995a. Seismic evaluation of concrete dams via continuum damage models. Earthquake Eng. Struct. Dyn. 24 (9), 1225-1245.

Cervera, M., Barbat, A.H., Hanganu, A., Oñate, E., Cirauqui, C., 1995b. Evaluación de la presión de fallo del edificio de contención de una central nuclear tipo PWR-W tres lazos. Parte I: metogología. Rev. Int. Métodos Numéricos para Calculo y Diseño en Ingeniería 11 (2), 271-293.

Clauss, D.B., 1989. Containment loading and failure modes. Presented at the IAEA Training Course on Accident Management in Nuclear Power Plants.

De Boeck, B., 1992. A review of containment accidents. Proc. 5th Workshop on Containment Integrity, May 12-14, Washington D.C., NUREG/CP-0120, SAND92-0173, pp. $37-50$. 
EPRI, 1989. Analysis of the Sandia one-sixth scale reinforced concrete containment model. Report EPRI NP-6261, Electric Power Research Institute, Palo Alto, CA.

Faria, R., Oliver, X., 1993. A rate dependent plastic-damage constitutive model for large scale computations in concrete structures. Monograph 17, International Center for $\mathrm{Nu}-$ merical Methods in Engineering (CIMNE), Barcelona, Spain.

Hanganu, A., 1997. Análisis no lineal estático y dinámico de estructuras de hormigón armado. Ph.D. Thesis, Universidad Politécnica de Catalunya, Barcelona, Spain.

Hanson, N.W., Schultz, D.M., Tang, H.T., 1989. Implications of results from full-scale tests of reinforced and prestressed concrete containments. Nucl. Eng. Des. 117, 79-83.

Hofstetter, G., Mang, H.A., 1995. Computational Mechanics of Reinforced Concrete Structures. Vieweg, Wiesbaden.

IDCOR, 1983. Containment structural capability of light water nuclear power plants. Tech. Rep. 10.1, The Industry Degraded Core Rulemaking Program.

Kupfer, H., Hilsdorf, K.H., Rush, H., 1969. Behaviour of concrete under biaxial stress. Proc. ACI 66 (8), 656-666.

Lubliner, J., 1990. Plasticity Theory. Macmillan, New York.
Lubliner, J., Oliver, J., Oller, S., Oñate, E., 1989. A plasticdamage model for concrete. Int. J. Solids Struct. 25 (3), 299-326.

Mang, H.A., Bićanić, N., de Borst, R. (Eds.), 1994. Computer Modelling of Concrete Structures. Proc. EURO-C Int. Conf., Pineridge Press, Swansea, UK.

Ngo, D., Scordelis, A.C., 1967. Finite element analysis of reinforced concrete beams. ACI J. 64, 152-163.

Oller, S., 1988. Un modelo de 'daño continuo' para materiales friccionales. Ph.D. Thesis, Technical University of Catalonia, Barcelona, Spain.

Oñate, E., 1992. Calculo de Estructuras por el Método de Elementos Finitos. International Center for Numerical Methods in Engineering (CIMNE), Barcelona, Spain.

Oñate, E., Oller, S., Oliver, J., Lubliner, J., 1988. A constitutive model for cracking of concrete based on the incremental theory of plasticity. Eng. Comput. 5 (3), 309-320.

Parks, M.B., Spletzer, B.L., Lambert, L.D., Weatherby, J.R., 1992. Containment performance experiments under severe accident loadings. Sandia National Laboratories.

Rubinstein, R.Y., 1981. Simulation and the Monte Carlo Method. Wiley, New York. 